FABRICATION AND CHARACTERIZATION OF CRYOGENIC TARGETS FOR INERTIAL CONFINEMENT FUSION

\author{
BY
}

HARRY RIEGER

KYEKYOON KIM

\author{
CHARGED PARTICLE RESEARCH LABORATORY \\ DEPARTMENT OF ELECTRICAL. ENGINEERING \\ UNIVERSITY OF ILLINOIS \\ URBANA, ILLINOIS 67801
}

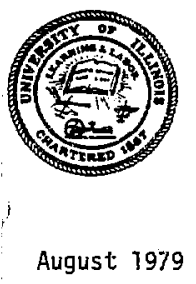

Research Sponsored By LAWRENCE LIVERMORE LABGRATORY Subcontract No: 8320003 


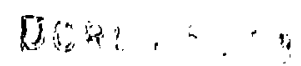

$S / C \# B 32003$

CHARGEO PARTICLE LABORATORY REPORT NO. 3-ï

\section{FABRICATION AND CHARACTERIZATION OF CRYOGENIC TARGETS FOR INERTIAL CONFINEMENT EUSION}
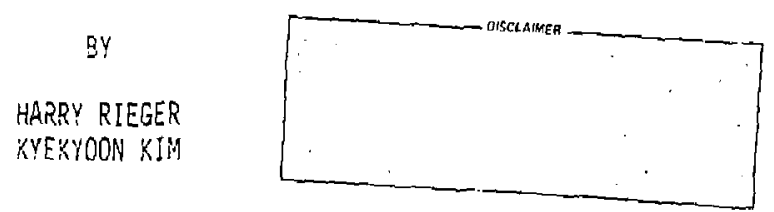

CHARGED PARTICLE RESERRCH LABORATORY

DEPARTMENT DF ELECTRICAL ENGINEERING

UNIVERSITY OF ILLINOIS

URBANA, ILLINOIS S1801

August 1979

Research Sponsored B:

LALRENCE LIVERMORE LABORATORY

Subcontract io. 8320003 
ACKNOWLEDGMENT

It is a pleasure to acknowledge the able assistance of Jim Fanning who was always willing to work with us when we needed his help. We would also like to thank Dr. C. D. Hondricks and Dr. T. P. Bernat at the Lawrence Livetmore Laboratory for their continued support and interest in this work.

The success of this work also depended on the assistance of many technica] people: in particular, Barney Marshall in the machine shop, Nick Vassos from the Coordinated Science Lab, Al Wilson and Ed Boose in the special processes lab, Bill Zuehsor and Steven Peters. They did a professional job with talent and experience for which we are grateful.

We thank Sara Jackson for a nice job she did tyoing and organizing the macerial.

This work was financially supported by the United States Department of Energy under the Lawrence Livermore Laboratory Subcontract 8320003. 


\section{ABSTRACT}

A new technique has been developed which is capable of fabricating uniform cryogenic targets for use in inertial confinement fusion. The essence of the technique is to directly wet a target with a cold helium gas jet, which results in freezing of the DT mixture (fusion fuel materiaT) contained in the target. A controlied amount of current is pulsed through a heater wire surrounding the target, giving rise to fast evaporation and refreezing of the $D T$-condensate into a uniform layer. The current technique is unique in that, unije other existing techniques, it does not require troublesome cryogenic shields, that it is capable of retaining the integrity of the cryogenic targets for as long as required, and that it is directly implementable with the room-temperature target chambers. This technique, therefore; opens up a new avenue in developing practical power-producing fusion reactors. Experiments, which have been performed with $0_{2}$-filled glass microshells, successfully produce uniform layers of both liquid and solid $\mathrm{D}_{2}$ inside the glass shells. A set of data illustrating the technique is presented and analyzed. 
TABLE OF CONTENTS

Chapter Page

1. Introduction ................ 1

2. Apparatus for Freezing Targets ...........6 6

3. Inspection, Selection, and Mounting of Targets at Room Temperature .............. 15

4. Diagnostics for Inspecting Cryogenic Targets ...... 20

5. Target Freezing Experiments - Results and Discussions ...................... 29

6. Conclusions and Suggestions for Future Experiments . . . . 40

Appendix I. Computer Printout of the Calculated Fringe

Patterns . . . . . . . . . . . 46

Appendix 11. Theoretical Calculation of the Amount of $\mathrm{D}_{2}$ -

Condensate Inside a Target .......... 53

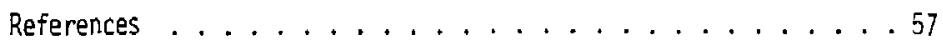


FIGURE CAPTIONS

Figure Page

1. Sequence in target implosions ............ 3

2. Target-freezing apparatus ........... 8

3. Schematic of cold jets-cold chamber apparatus . . . . . . 10

4. Schematic of cold jet apparatus ........... 12

5. Flow control of the helium gas jet .........13

6. Mach-Zehnder interference microscope for target selection ................. 16

7. A typical batcin of $0_{2}$-filled glass microshells ..... . 11

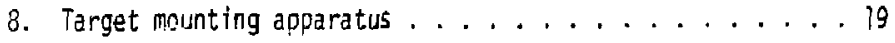

9. The diagncstic system for analyzing the target . . . . . 21

10. Ray tracing of Mach-Zehnder interferometer . . . . . 22

11. Room temperature target ............. 22

12. Ray tracing of room temperature target ........ 24

13. Ray tracing of cryogenic target . . . . . . . . . . . 21

14. Surface tension of hydrogen ................ 31

15. Picture of a target mounted on a glass stalk placed in front of the cold helium gas jet nozzie..... . 34

16. The target with no condensate................ 34

17. The beginning of condensation ................ 35

18. The effects of different positioning ........ . 35

19. Droplet moved toward the nozzle opening . . . . . . . . 36

20. A thick layer of jiquid . . . . . . . . . . 38

21. The optical setup using holography ........ 43

22. The optical setup for obtaining Fourier transfomation . . 45 


\section{CHAPTER 1}

\section{INTROOUCTION}

One of the useful energy sources for the future is the fusion reaction that occurs in hydrogen isotons, like deuterium $(0)$ and tritium $(T)$. This fusion reaction releases a substantial amount of energy ${ }^{(1)}$ :

$$
\begin{aligned}
& D \equiv{ }^{2} \mathrm{H} \\
& D+D \longrightarrow{ }^{3} \mathrm{He}(0.8 \mathrm{Mev})+n(2.5 \mathrm{Mev}) \\
& 0+\mathrm{D} \longrightarrow T(1 \mathrm{Mev})+\mathrm{D}(3 \mathrm{Mev}) \\
& D+T \longrightarrow{ }^{4} \mathrm{He}(3.5 \mathrm{Mev})+n(14 . \mathrm{Mev}) \\
& n+{ }^{6} \mathrm{Li} \longrightarrow{ }^{4} \mathrm{He}(2.1 \mathrm{Mev})+T(2.7 \mathrm{Mev})
\end{aligned}
$$

Reaction (4) uses neutrons to breed tritium which is required for reaction (3).

The hydrogen isotopes can not fuse together unless their kinetic energies are sufficiently high $(2)$. For reaction (3), the required kinetic energy for ignition is in the order of $5 \mathrm{keV}(\mathrm{cf}$. lev $=11,600 \mathrm{k})$. To sustain fusion reactions, the probability for fusion events to occur has to exceed a certain level. This probability depends upon the density of ions, their confinement time, and their collision cross-section at a given temperature. To be more specific, a convenient criterion for unceasing fusion reaction is that the product of $n$ and : take on certain threshold values for each fusion reaction:

$$
\begin{aligned}
& n \cdot \tau>10^{16}\left(\mathrm{sec} / \mathrm{cm}^{3}\right) \text { for } D-0 \\
& n \cdot:>10^{14}\left(\mathrm{sec} / \mathrm{cm}^{3}\right) \text { for } D-T
\end{aligned}
$$

where $n$ is the density of ions $\left(\mathrm{cm}^{-3}\right)$ and $\mathrm{t}$ is the appropriate fuel ion confinement time. The above requirement is known as the Lawson Criterion. Since the ignition temperature for fusion is so high $\left(-10^{8} \mathrm{k}\right)$, it is necessary to find a way to confine the highiy energetic ions. There are two major ways of doing so: 
the magnetic confinement and the inertial confinement. One of the most convenient ways of achieving inertial confinement is the laser fusion.

The laser technology is advancing very rapidly, and high power lasers are currently available for a variety of applications. But the efficiency of these lasers is usually too low to be a good power source for fusion ignition. For laser fusion, several beams coming from different directions are focused onto a small target of OT in a spherically symmetric manner (Fig. 1).

The Lawson Criterion, when translated into a requirement for laser fusion, is

$$
p R>1 \mathrm{gr}^{\prime} \mathrm{cm}^{2}
$$

because the atoms' ?ifetime

$$
\tau \cong R / V_{S}
$$

:here $o$ is the mass density of the pellat $\left(\mathrm{gr} / \mathrm{cm}^{3}\right), R$ is the radius of the pellet, and $y_{S}$ is the velocity of the compression wave propagating toward the center of the pellet.

A laser pulse that can provide $10^{12}$ Watts in a period of a nanosecond can yield an implosion pellet density as high as 10,000 times that of liquid. The pressure at the pellet surface can go as high as $10^{8}$ atm. (3) The pulso length of the laser has to be short so that the plasma at the surface of the target, due to the high energy absorbed, may not reflect the incoming iaser beams. The energy absorbed at the surface produces fast ablation, which, in turn, compresses the target. When the target reaches high enough density, fusion reaction occurs, and energy is released through emission of radiation.

Compression of solid fuel pellets is not considered to be efficient due to the back pressure built up inside the pellet. A more efficient way of achieving high compression is by using hollow targets.

A concentric hollow sphere of solid or liquid DT can be compiressed more 
(a)

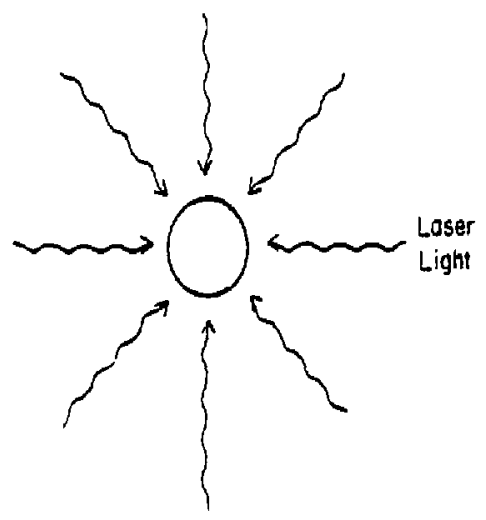

(b)

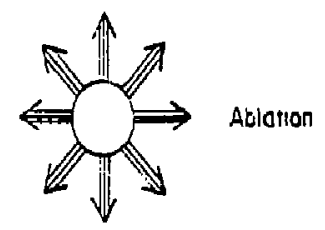

(c)

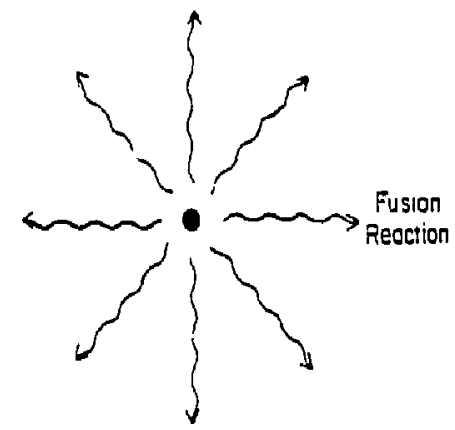

Fig. 1 - Sequence in target implosion; (a) pulsed laser beams hitting the target; (b) target implosion due to the rocket-like effect of ablation; (c) radiation released by fusion reaction. 
efficiently. In compressing a hollow sphere, the stell gets acceler, $x^{\text {ted }}$ toward the center without building up much counter pressure inside the shell. Therefore, the momentum added to the shell yields higher fuel density. The uniformity in shell thicikness of a hollow sphere is essential for achieving high density. The implusion force acting on the surface of the sphere is uniform assuming even intensity of the laser light incident on the surface. The mass per unit area of the suriace, therefore, has to be uniform in order to achieve symmetris compression of fuel material toward the center point. A nonuniform thickness will result in lower fuel density for this reason.

A promising technique to fabricate hollow targets is to use a glass microshell filled with highly pressurized DT gas. Since a high percentage of input energy is desired to be delivered to the fuel mass, the size of this DT-fillad glass microshell has to be very small ( $50 \mathrm{\mu m}$ to $300 \mu \mathrm{m}$ in diametar). The thickness of the target is a few micrometers, and the DT-fill pressure at $300 k$ is anywhere from $50 \mathrm{~atm}$ to $300 \mathrm{~atm}$. Selecting targets with uniform giass shells requires advanced interferometric observation. Steady positioning of a target also involves some fine-control mechanism before it can be mounted on a glass sialk. To freeze the DT contained in a glass microshell target, the target has to be cooled down to a temperature below $20 \mathrm{~K}$. This, of course, requires one to be equipped with high yacuum technology and cryogenic capabilities. Detailed observation at different temperatures of a target being frozen requires an accurate diagnostic system. To fabricate highly efficient targets, a perfectly uniform layer of ot has to be obtained (a few hundred angstroms in thickness variation).

As a first step, the capability of freezing OT gas inside a target is to be achieved. In the present investigation, a combination of cold helium gas jets and cold chamber will first be employed to freeze the target. After studying the behavior of liquid and solid DT on the formation of a uni form layer, a new system is then designed which uses the cold helium jet only, and which, therefore, can 
operate inside a laser firing target chamber. As a result, a uniform layer of DT wit1 be formed inside a chamber at room temperature.

The advantages of these new target fabrication techniques are:

(1) The target can be cooled down, and the entire surface of the target can be exposed to the laser beams.

(2) By keeping the cold gas jet on, the fozen layer of OT is in steady state, i.e., the retention time for the DT layer is infinite. This means that there is nu time limitation required for the target to be fired. In conjunction with this, we note that in other target freezing techniques ${ }^{(4)}$ the DT layer retention time is on the order of $100 \mathrm{msec}$.

(3) Different relative positioning of the target and the jet, combined with different jet flaws, gives a control over the thickness of the uniform Tiquid layer.

Chapter 2 presents a detailed dascription of the systems used for fabricating hollow targets. Chapter 3 describes a methor by which the targets are selected and mounted on a glass stalk. Chapter 4 gives the diagnostics used for inspecting the targets bsing frozen. Chapter 5 presents a discussion of the experiments, data collection, and their interpretation. The final chapter (Chapter 6) gives concluding remarks and suggestions for future investigations. 
CHAPTER 2

\section{APPARATUS FOR FREEZING TARGETS}

Fabrication of cryogenic targets requires some special means. A key element for an apparatus which will do such fabrication is liquid hel ium, which has a boiling temperature of $4.2 \mathrm{~K}$ at atmospheric pressure. Maintaining such a low temperature inevitably requires thermal insulation.

This chapter describes the working components and the reasonino behind the design of two different target frepzing apparatus. The first apparatus uses cold helium jets, which are tharmally shielded by a cold chamber. The second one employs a sing?e cold helium jet, and the free:ing cell walls are maintained at room temperature.

\subsection{Apparatus Requirements}

In order to solidify the contents of the glass microshell, namely, the $D_{2}$ gas in the current experiment, one must cool down the microshell to a temperature below $18.7 \mathrm{~K}$, the triple-point temperature of $\mathrm{D}_{2}$. This requires that the temperature of the cooling gas jets be below $18.7 \mathrm{~K}$. Also, if a uniform liquid layer of $\mathrm{D}_{2}$ is required, the flow rate as well as the temperature of the jets need to be adjusted to create the appropriate thermal environment around the target.

Maintaining a low pressure in the surrounding area of the target is essential if one wants to achieve the most efficient ccupling in the target chamber between the target and the incident laser beams focused onto it.

\section{2 - The Liquit-Helium-Cooled HFat Exchanger}

The boiling point of liquid helium at atmospheric pressure is $4.2 \mathrm{~K}$, which makes it effective as a coolant in producing the required cold gas jets. Since 
it is important in the current investigation to have the capability to controt the jet tcmperature, a licuid-hel ium-cooled heat exchanger was used to cool joun ultra-inigh purity helium gas, the gas employed to produce the cold jets. A schematic 's this is contained in Fig. 2.

The heat exchanger is fabricated out of an OFHC copper block and its colinarical bores are filled with copoer leads for efficient heat transfer. The hel ium gas flows through the center portion of the heat exchanger. This section was kept cooi by the surrounding sertion that contains liquid helium. The liquid helium is transferred from a pressurized liquid nelium dewar and forced through the heat exchanger. By choking this at the exhaust end, one then achieves a convenient control of the temoerature of the heat exchanger. A tubing with a dead end, which is filled with hydrogen gas, is in thermal contact with the heat exchanger at the exit end. Ey measuring the vapor pressure of the hydrogen gas in the tubing, one can measure the temperature of the heat exchanger at the exit end.

It is essential to minimize the heat transfer from the room temperature outside wall to the heat exchanger. To eliminate the conductive heat transfer, the heat exchanger was shieided by a thermal jacket that holds a nigh vacuum $\left(\sim 10^{-7}\right.$ Torr). To minimize the radiative heat transfer, the heat exchanger was golo plated resulting in high reflectivity.

\section{3 - Target Freezing Cell Featuring Cold Jets-Cold Wall Combination}

The first s.stem designed to fabricate a uniform oT-layer was a cold chamber equipped with cold jets. The main considerations in choosing this particular design were: first, to el iminate possible heat conduction from the chamber wall to the target; and second, to have the capability of cooling evenily the entire surrounding area of the target. 


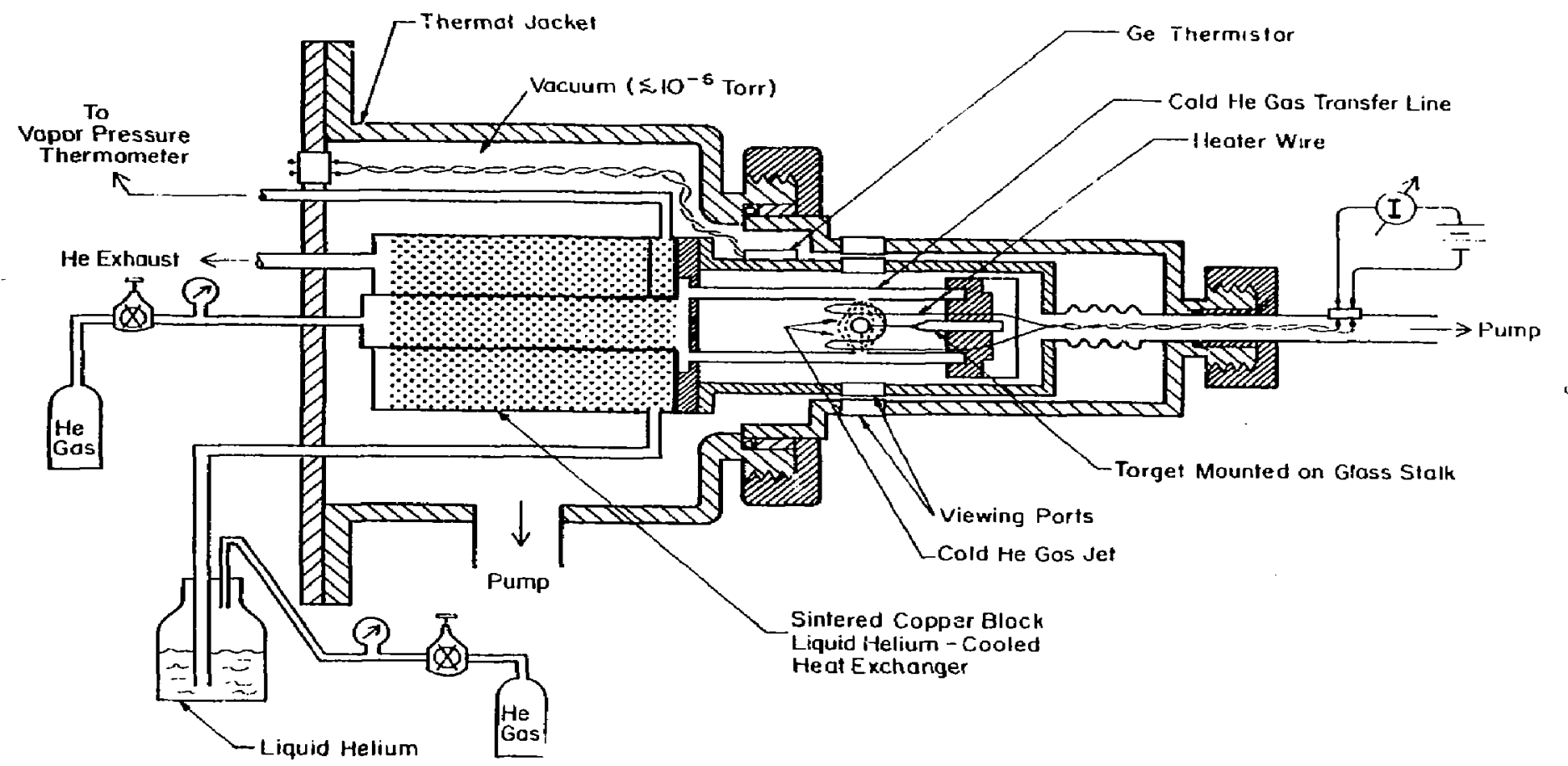

Fig. 2 - Target-freezing apparatus 
Figure 3 show: a scherdic of the apoardus. The chamber that housas the target was made out of copner and attached directly to the heat exchanger to obtain as low a temperature as possible. Indium wis uses to seal the cold chamber to the neat exchanger. Two stainless steal tubes inside the coid chamber bring the cold helium aas from the heat exchanger to the vicinity of the tarnet. The suspension of the cryogenic parts in the vacuum chamber was made possible by using thin-walied stainiess steel tubing and bellows to minimize the heat conduction.

Quartz windows (1/16" thick) were used to view the sarget, ahich gave rise co low aberration. To overcome the differences in expansion and contraction between the copper and the quartz, small windows $\left(\sim / 4^{\prime \prime}\right.$ in dianeter) were used, which were epoxied to the chamber wall using Armstrong A-12 brand. inis Darticular epoxy was chosen among many different brands because of its effec:iveness at cryogenic temperatures.

studying the optimal conditions for obtaining uniform cryugenic targets requires very accurate temperature and pressure diagnostics. A thermocouple pressure gauge was used at the exhaust pcrt of the cold chamber to measure tine pressure. For temperature measurements, a copper-constantan themocouple was employed. This junction was placed $\sim 0.5 \mathrm{~mm}$ from the glass microshell to obtain the temperature reading of the target as accurately as possible. The use of a compensating junction with an amplifier allowed us to measure the temperature within accuracy of $1 \mathrm{k}$.

A heater wi:? was mounted next to the ball to allow for temporary vaporization of the $\mathrm{I}_{2}$-condensate inside the target. The current and the duration of the current pilse through the heater wire were made variable and couid be preselected. 


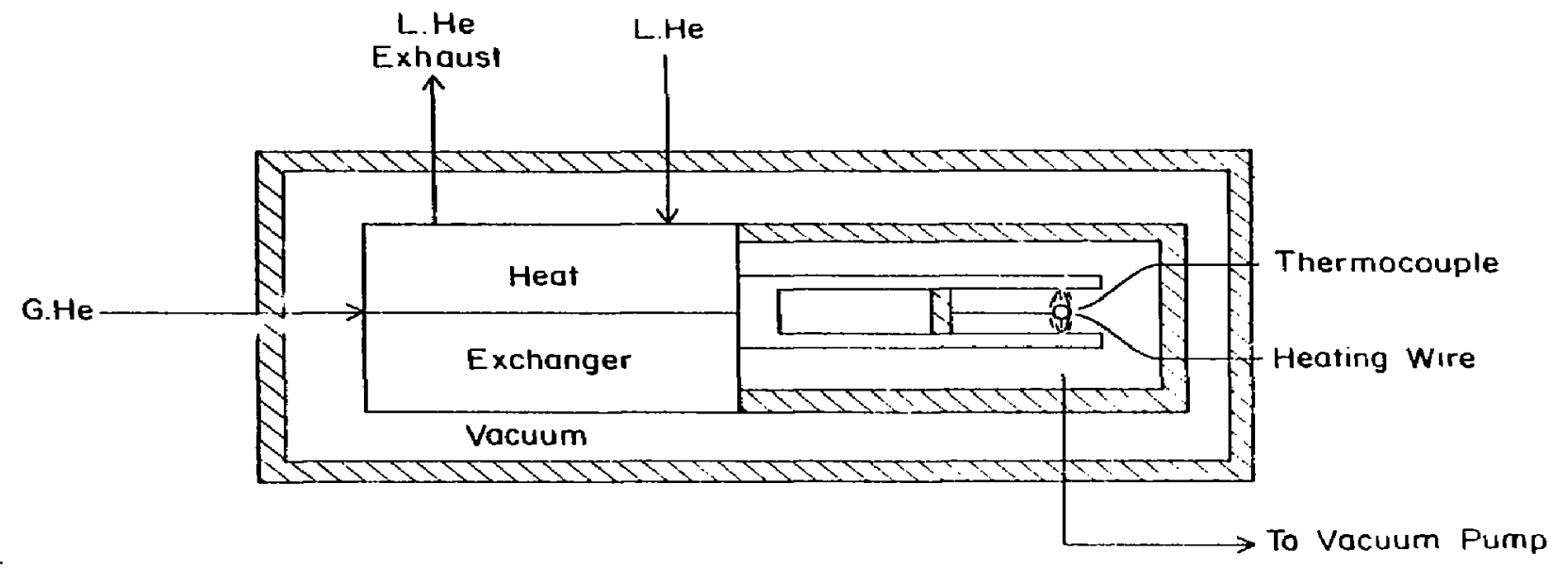




\section{$2.4-$ cold det Apparatus}

he purpose of fabricating cryogenic ta agets is to itudy their eficiciency and cilaracteristics as laser fijsinn targets in the torget chamber during laserinduced impirsion. in using the cold jets-cold chamber combination apdaratus, one faces the difficulty of having to expose the crjogenic target to the laser beams without impairing its integrity, It is without a doubt a formidable task to remove the cold chamber and fire the target, all within the lifetime of the cryogenic target $(-100 \mathrm{~ms})$. Therefore, a second apparatus was proposed, which is designed to use a cold jet on?y withou: having recourse to an intermediate cold chamber for thermal shielding.

A schematic of this apparatus is shown in $\mathrm{Fig}$. 4. The heat exchanger and the jet tubes are separated from the freezing cell and housed in a high vacuum jacket. in this way, one can meinta in efficient cooling of the heirum gas. The target is mounted in a chamber whose walls are maintained at room tenoerzture. The $x-, y-$, and $z$-micrometer manipulators provide the flexibility in positioning the target.

In order to minimize heat conduction from the walls to the target, the chamber has to be evacuated at a high pumping rate. Using a wide exnaust port $\left[\sim ?\right.$. s" $^{\prime}$ in diameter) and a high capacity vacuum pump $(\sim 10001 / m i n)$, a iow enougin pressure could be maintained.

The accompanying diagnostics for the measurement of pressure and temperature, and the heater wire unit were similar to the ones used in the previous section.

In order to operate this system on a pulsed basis, i.e., turning on the jet for a certain period of time that is required to freeze the $D_{2}$, two solenoid valves with a time control were added (Fig. 5). The two solenoid valves are ac- 


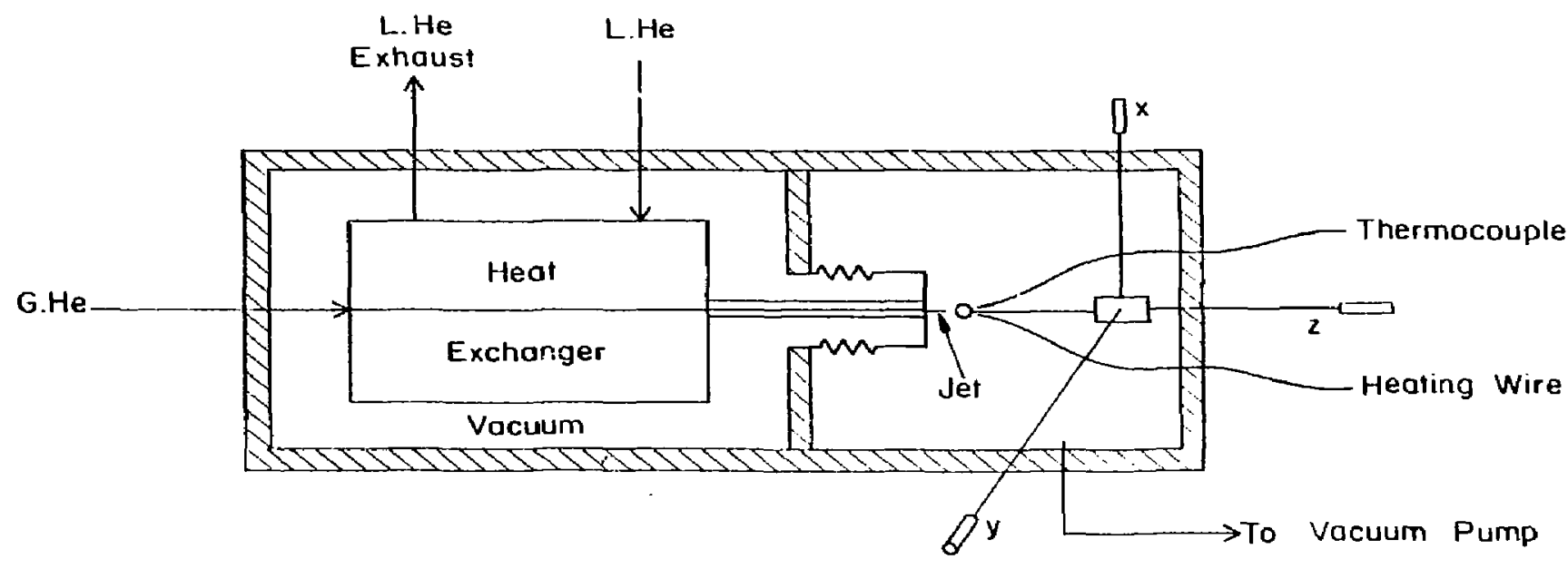

$\vec{n}$

Fig. 4 - Schematic of cold jet apparatus. 


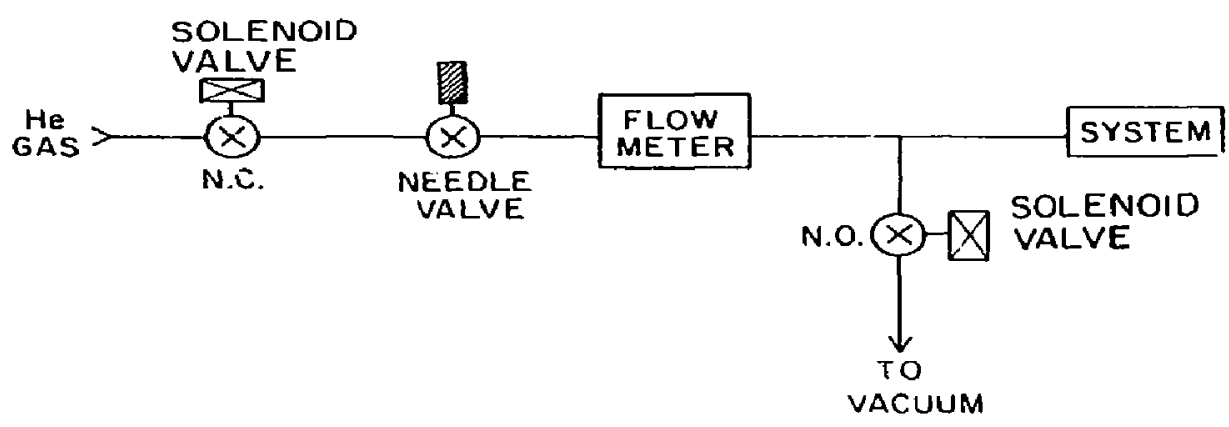

Fig. 5 - Flow control af the heliun gas jet. 
tivated simutaneously either with a cortrolled time delay between them, or manuaily. An advantage of a system 7 ike this is that freezing of a $\mathrm{O}_{2}$-filled target and firing of the laser can be dane without any interruption inside the laser firing tarçet chamber.

The system is not complete without having the capabi?ity of observing the targat while it is being frozen. Since the size of the target is so small, it has to be magnified opticaliy, roughly by a factor of 1000 before it can be conveniently visualized and inspected, This means that a microscope objective has to be placed close enough to the target $(\sim \rightarrow \mathrm{mm})$, For detailed observation of the frozen $\mathrm{O}_{2}$-layer, Mach-Zehnder interference microscope was used (detailed description is given in Chapter 4$)$. 
VIHATER:

INSPECTION, JELECTION, ANO MOUNTIHG OF TARGETS HT ROON TEMPERATURE

To have a desired target mounted on a glass stalk, a side technology was developed out of the main experiment. A special and rery delicate technique had to be develaped for inspecting the glass microsinelis, selecting the one that meets the desired requirements, and mounting it on a very fine edge of a glass stalk. This chapter descrihes the special tools and techniques that were deveioped and used for the target mounting.

\section{1 - introduction}

The technique used to manufacture the glass microsher ${ }^{(5)}$ does not pro. duce good uniformity in the wall thickness. At random, some of the balls ale uniform enough to have fluctuations in the wall thtckness less than $3000 \&$. A reliable analysis of the frozen layer inside the $a_{2}$-filled target requires ane to select through inspection a uniform glass microshell to work with. The selected target is then mounted on a glass stalk $(-40 \mu \mathrm{m}$ in diameter at the tip) so that the disturbances due to cooling can be minimezed and tite exposed portion of the target for anziysis is maximized.

\subsection{Mach-2ehnder Interference Microscope Target Selector}

The use of interferometry was incorporated into the inspection of targets, which proved to be very conventent, fast, and accurate. A Mach-Zehnder interferometer was used (Fig. 6). The beam 5plitters (B.S.) and mirrors (M) split up the laser bean into two. One beam was steered to go thmough a batch of glass microshells placed on a glass inspection plate, white the other was made to bypass it. The two beans were then recombined at the and of the interferometer to 


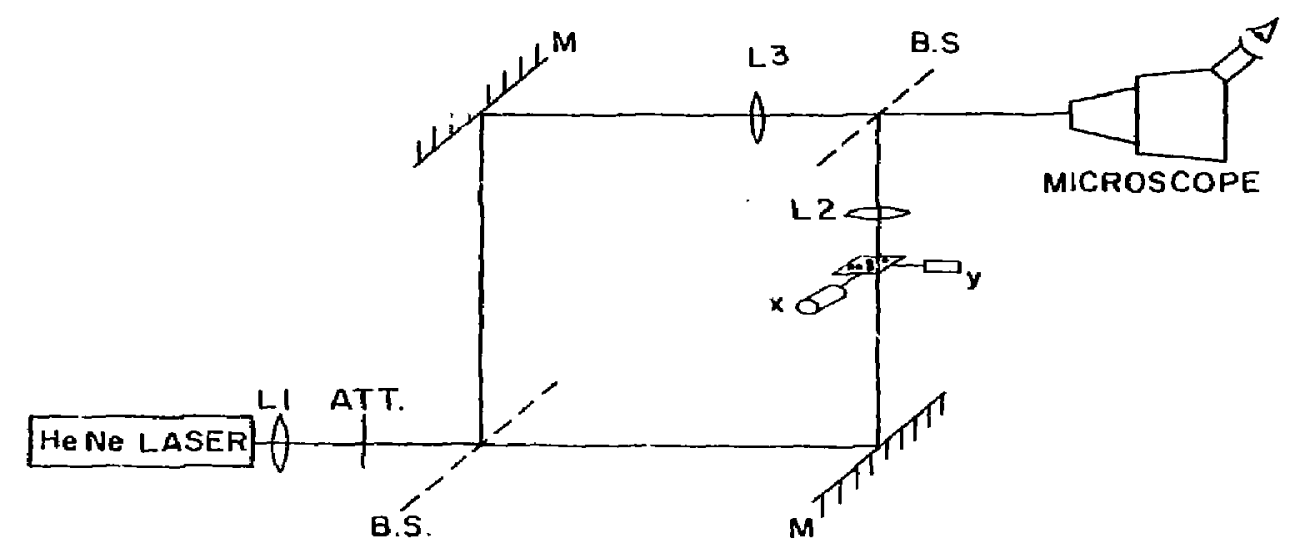


give rise to fringes resulting from the optical path length differences la complete analysis is given in Chapter 4).

Magnification of the glass microshells was achieved in the following manner. An objective lens (L2) and a microscope with a variable magnification were used on one arm of the Mach-Zehnder interferometer to obtain the required image size of the balls. Another identical objective lens (L3) was then positioned in a symmetric manner on the other arm of the interferometer to compensate for the distortion caused by L2. An attenuator and a lens (L1) were placed in front of the He-Ne laser to provide a vider beam, which is necessary to view simul. taneously a large number of glass microshells and to provide low enough intensity for comfort in viewing.

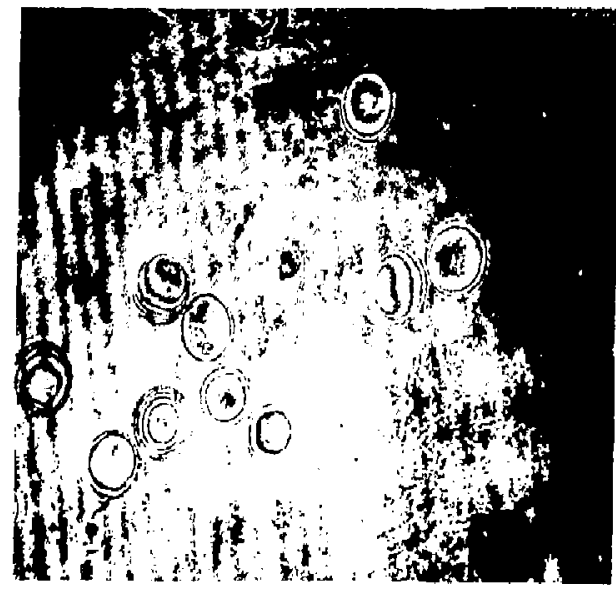

Fig. 7 - A typical batch of $D_{2}$-filled giass microshells.

Figure 7 shows a typical batch of glass microshells being inspected by using the Mach-Zehnder interference microscope. $x$ - and y-micrometer man- 
ipulators (Fig. 6) attached to the inspection plate, that hoids the glass microshells, enable one to inspect a wide variety of balls.

\section{$\underline{3.3 \text { - Target Mounting }}$}

Once a uniform glass microshell has been spotted, it has to be picked up. A vacuum chuck (Fig. 8) was constructed and employed to handle the ball. For ease as well as accuracy in the ball-maneuvering, $x-, y$-, and z-micrometer manipulators were used. The inside diameter of the vacuuin chuck tube must be smaller than the diameter of the selected target. When a vacuum was applied to the vacuum chuck, the suction grabted the ball as the open erid of the chuck was moved next to the selected target. Applying a vacuum to a hollow glass stalk, and positioning a tiny amount of epoxy (Amstrong A-12) at the very tip of the stalk, the suction pulled some of the epoxy into the stalk. Using the micrometer manipulators of the glass stalk and the vacuum chuck, the tip of the glass stalk was positioned next to the target. By controliing the exhaust opening, and allowing a small flow of gas from the high pressure tank into the stalk, a controlled amount of epoxy was forced out of the glass stalk. ReTeasing the vacuum from the vacuum chuck leaves the target bound to the glass stalk. 


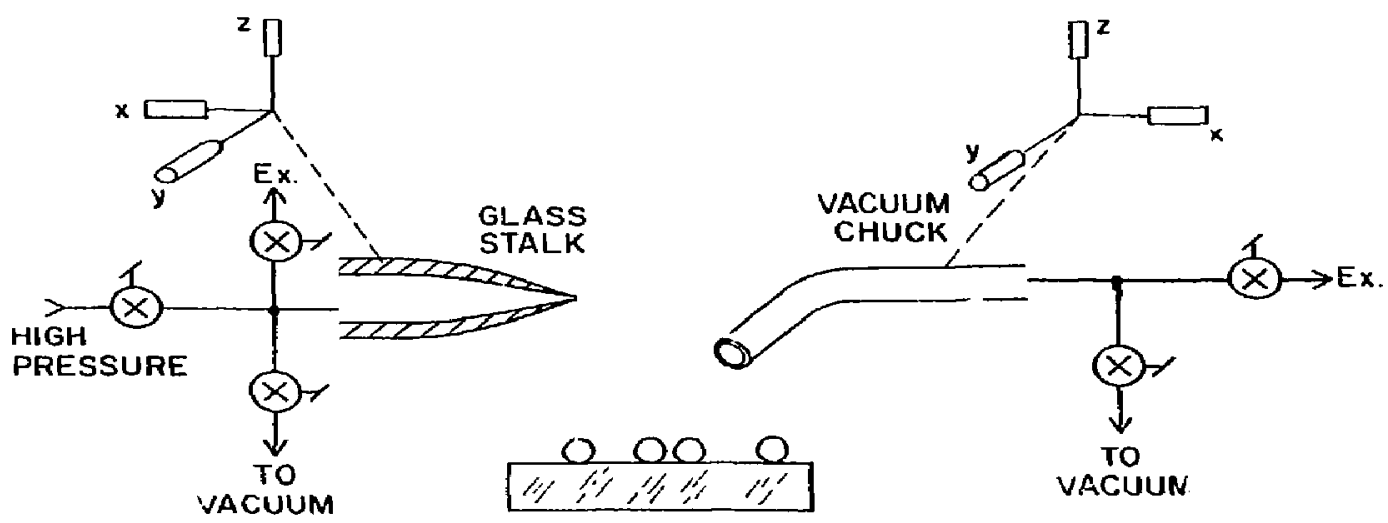

Fig. 8 - Target mounting apparatus. 
CHAPTER 4

OIAGNOSTICS FOR INSPECTING CRYOOENIC TARGETS

Inspection of the uniformity of a cryogenic target is very delicate because the target size and thickness are very small, the frozen ?ayer of $D_{2}$ occurs $i_{i-}$ side the glass microshell, and the inspection must be done continuously as the experiment progresses. For these reasons, the use of an interferumetric technique was an essential part of the diagnostics.

This chapter describes the interfermetric technique used and some of the calculations upon which the technique is based.

\section{I - Mach-Zehnder Interference Microscope}

The key apparatus us ad to analyze the uniformity of th. frozen tarnet was a Mach-Zehnder interference microscope similar to the one described in Chapter 3. A schematic of this is contained in Fig. 9. A He-Ne laser (in this setuo,

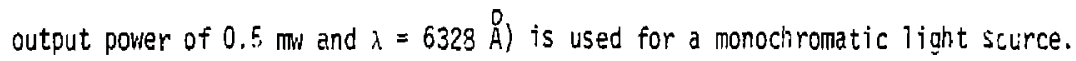
An iris is then placed in front of this to cut off the portion of the beam thet has an uneven intensity. The two mirrors placed after the iris steer the laser beam onto the target. The two-mirror configuration gives rise to flexibility in illuminating the target from different angles, which enables one to direct the beam properly inside the interferometer. Fil increase in the illumination intensity on the target is achieved iy a lens of lonq focal length placed in front oi the interferometer.

By first splitting the coherent monochromatic bean into two, but later recombining them back tagether, the same intensity distribution would be obtained. However, if we insert the glass microsheil into one of the beam paths (Fig. 10), the light going through the glass microshell will be slowed down. Slowing down 


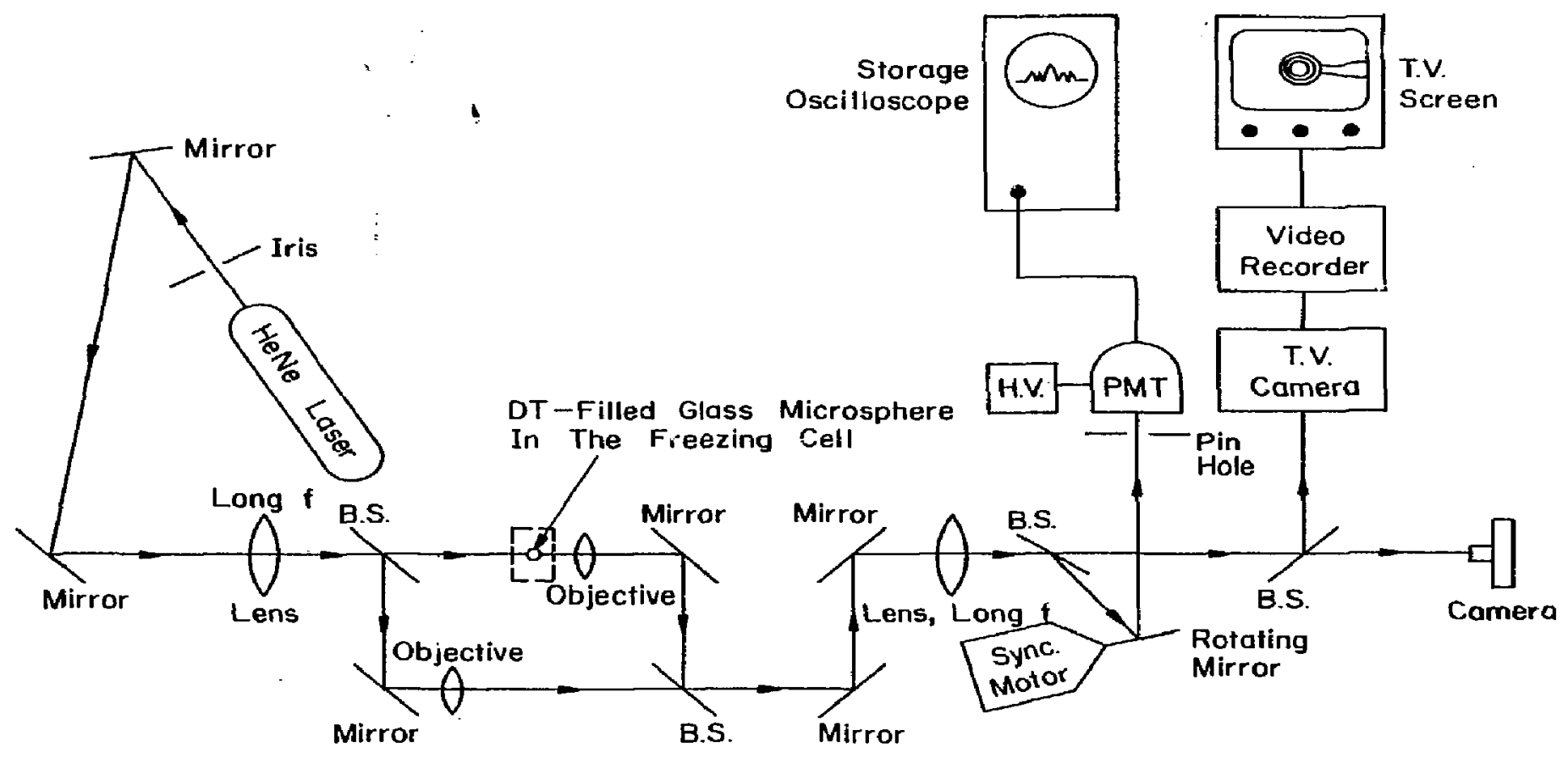

Fig. 9 - The diagnostic system for analyzing the target. 


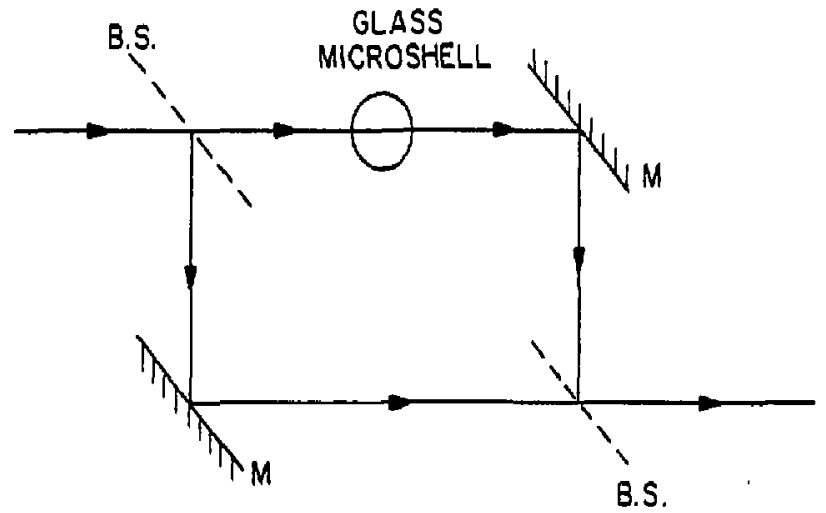

Fig. 70 - Ray tracing of Mach-Zehnder interferometer.
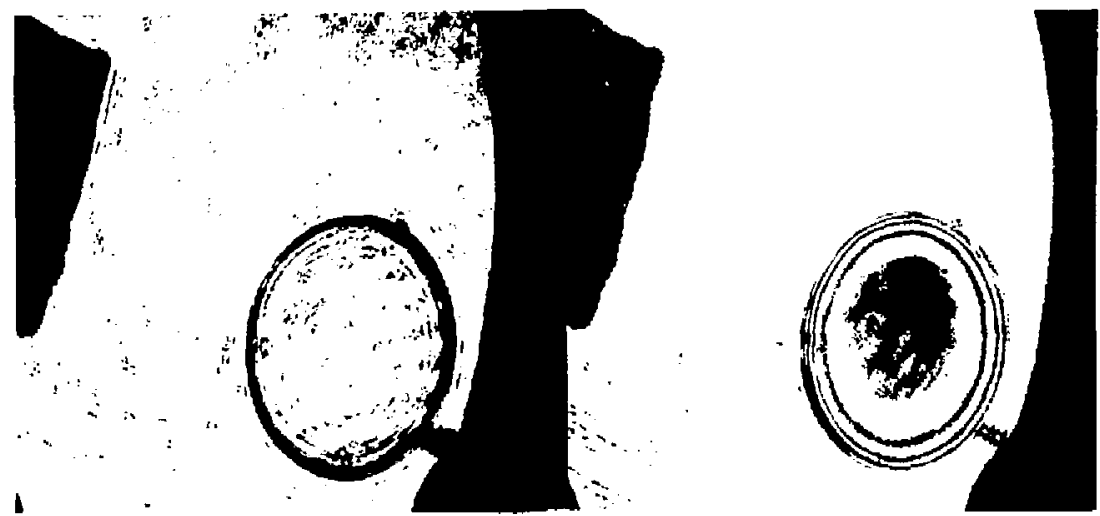

(a)

(b)

Fig. 11 - Room temperature target: (a) Shadow micrograph

(b) Interference micrograph. 
has the same effect as propagation at the same speed for a longer distance. Since the laser light is coherent, an additional distance of $(i+1 / 2)$ : $(i)=0,1,2, \ldots)$ causes the lignt intensity to go to zero after the two beams have recombined. An additional distance of it, of course, results in the same intensity as the incoming beam.

The cross-section of a glass microshell ( $F$ ig. 12) shows that the effective additional distance in the optical path length changes as we go from the center point to the edges. Therefore, for a spherical glass shell of uniform wall thickness, symmetrical circular rings result (Fia. 11 ).

\section{2 - Analysis of Fringe Patterns ${ }^{(6)}$ for a Room Temperature Target}

Since the Mach-Zehnder interference microscope target-sorter described in Chapter 3 enables us to select the uniform glass microshells, the analys is that follows will be for uniform glass microshells only.

Figure 12 shows the path of a ray incident on a target a distance $d$ from the center. At room temperature, the $D_{2}$ gas inside the target has an index of refraction $n_{3^{*}}(7)$

$$
\sin x=\frac{d}{R} \quad,
$$

where $R$ is the radius of the glass microshell. Using Snelt's law

$$
\frac{\sin a}{\sin a}=\frac{1}{n_{T}},
$$

where $n_{1}$ is the index of refraction of glass. 


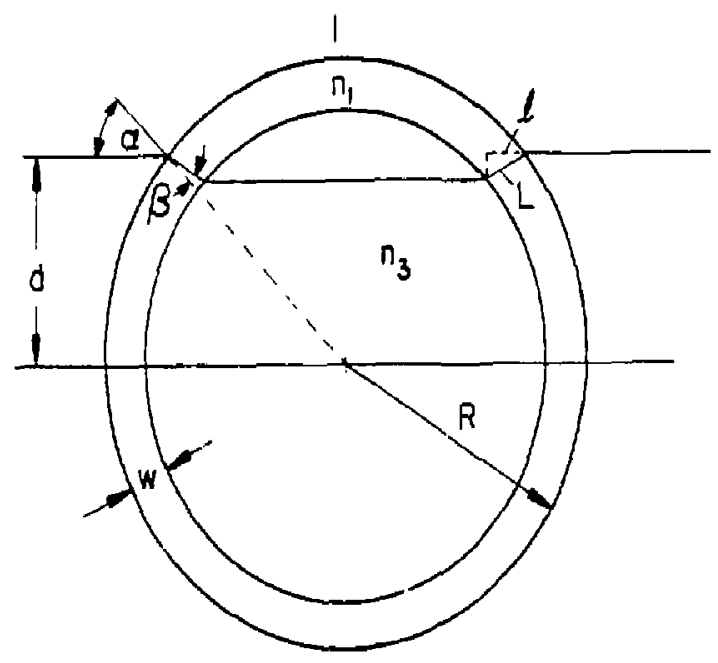

Fig. 12 - Ray tracing of room temperature target.

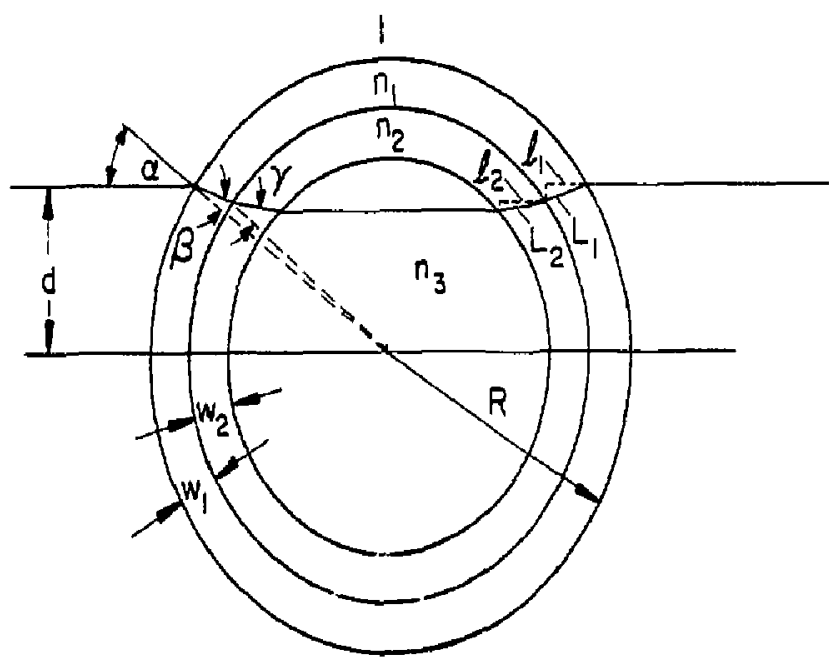

Fig. 13 - Ray tracing of cryogenic target. 
Therefore,

$$
z=\sin ^{-1}\left|\frac{d}{n_{n}}\right|
$$

For the targets we used, "w is the glass shell thickness; $w_{1} \cdots R$, so,

$$
\iota=\frac{w_{1}}{\cos 3}
$$

Since $w_{1} \leftrightarrow R$ and $n_{3}=1$, we can assume that the ray propagate parallel to the optical axis.

The effective path length through the glass is

$$
2 L n_{1}=\frac{2 w_{1} n_{1}}{\cos \hat{B}}
$$

Without going through the glass, the path would have been $2 l$.

$$
\frac{l}{L}=\cos \left(a-\frac{Q}{2}\right) .
$$

Therefore,

$$
2 \ell=\frac{2 W}{\cos \beta} \cos (\alpha-s) .
$$

The path length difference through the shell is $\Delta S_{1}$,

$$
\Delta S_{1}=2 L_{1}-2 \ell=\frac{2 w_{1}}{\cos 2}\left[n_{1}-\cos (\alpha-\dot{\alpha})\right] .
$$

The path length inside the shell is

$$
U \simeq 2\left(R-W_{1}\right) \cos \theta .
$$

The path length difference inside the shell is

$$
\Delta S_{3}=\left(n_{3}-1\right) U=\left(n_{3}-1\right) \quad 2\left(R-w_{1}\right) \cos \alpha .
$$


Combining Egs, $(4,8)$ and $(4.10)$ gives the desired optical path length fifference is.

$$
\therefore S=2 S_{1}+\Delta S_{3}=\frac{2 w_{1}}{\cos 3}\left[n_{1}-\cos (x-i)+2 ! n_{3}-1\right)\left(R-w_{1}\right) \cos x .
$$

For a given target, $\Delta S$ is a function of $d$ only. When $i S=N$, a bright ring is observed, and when $i S=N \lambda+i / 2$, a dark ring results.

A computer program (see Appendix I), using the given values of $R, n_{1}$, and $\Pi_{3}$ as an input, calculates the fringe patterns across the target for different values of $w_{1}$. By comparing the computer printout with the interference filicrograph (Fig. $11(\mathrm{~b})$ ), the thickness of the target can then be determined, and used for the analysis of a frozen target.

\section{3 - Analys is of Fringe Patterns for a Cryogenic Target}

As the temperature of a OT-filled glass microshell target changes, as long as there is no liquefaction of DT, the fringe pattern should remain as it is at room temperature $\left(n_{3}\right.$ is a function of density only). But, when a iqquid or solid DT is formed, $w_{2}, n_{3}$, and $n_{2}$ (Fig. 13) all vary. The temperature of the target determines the vapor pressure inside the ball, of which $n_{3}$ is a function. The remainder of the gas has been liquefied and has a certain mass density ${ }^{(3)}$ corresponding to the temperature. $n_{2}$ and $w_{2}$ can therefore be calculated (Appendix II).

Figure 13 shows the ray tracing for a cryogenic target. Using the same approach that was used for the room temperature target

$$
\frac{\sin y}{\sin \varepsilon}=\frac{n_{1}}{n_{2}} .
$$


Using Eqs. (4.2) and (4.12) resuits in

$$
y=\sin ^{-1}\left(\frac{\sin \frac{\alpha}{n_{1}}}{1}\right) .
$$

Considering the case where $w_{2} \lll R$

$$
L_{2}=\frac{W_{2}}{\cos y}
$$

The effective path length through the frozen layer is

$$
2 L_{2} n_{2}=\frac{2 H_{2} n_{2}}{\cos y}
$$

Without going through the fozen layer, the path length would have been $2 l$,

$$
2 R_{2}=2 L_{2} \cos (\alpha-\gamma)=\frac{2 w_{2}}{\cos y} \cos (\alpha-\gamma) .
$$

The path length difference through the frozen layer is

$$
\Delta S_{2}=2 L_{2} n_{2}-2 \dot{\zeta}_{2}=\frac{2 W_{2}}{\cos \gamma}\left[\mathrm{n}_{2}-\cos (\alpha-\gamma)\right] \cdot(\alpha, 17)
$$

The modified path length difference inside the shell is

$$
\Delta S_{3}=\left(n_{3}-1\right) 2\left(R-w_{1}-w_{2}\right) \cos a
$$

Combining Eqs. (4.8), (4.17), and (4.18) gives the desired optical path length difference $\begin{aligned} \Delta S=\Delta S_{1}+ & \Delta S_{2}+\Delta S_{3}=\frac{2 w_{1}}{\cos \beta}\left[n_{1}-\cos (a-\beta)\right] \quad(4.19) \\ & \left.+\frac{2 w_{2}}{\cos \gamma}\left[n_{2}-\cos (\alpha-\gamma)\right]+2\left(n_{3}-1\right)^{\prime} R-w_{1}-w_{2}\right) \cos \alpha .\end{aligned}$ 


\section{4 - Rotating Mirror-Pinhole-P.M.T. Combination}

A quantitative analysis of the fringe pattern is desired to characterize the uniformity of the frozen layer. A rotating mirror was used to scan the center line of the target fringe pattern across a pinhole (Fig. 9). The light intensity after the pinhole was detected by a photomultiplier tube. The electrical signal out of the P.M.T. was displayed on a storage oscilloscope. By measuring the symmetry of the signal, the uniformity of the target could be inspected.

A drawback was that the noise level of the signal due to the 1ight diffraction and the low light intensity was too high to give rise to the required resolution for inspection. Due to this difficulty, a new system was proposed which utilizes the analog signal out of a television camera.

\section{$4.5-$ Minicomputer Sys tem}

The video system used for observation and recording of the experimental events (Fig. 9) can also be used for a quantitative analysis of the iringe pattern. The analog signal out of the television camera can be picked uf and displayed on an oscilloscope. But it can also be converted into digital codes, stored, plotted, and compared against the theoretical calculations. A minicomputer system has been designed and is under construction to serve alt these functions. 


\section{CHAPTER 5}

\section{T'RRGET FREEZIIIG EXPERIMEIIT - RESULTS ANID DISCUSSIOHS}

The expericients were performed on two different systems. A system with cold jets-cold chamber combination was first employed to study the benavior of a $\mathrm{C}_{2}$-filled glass microshell at cryogenic temperatures. Behavior of a $\mathrm{O}_{2}$ filled glass microshell at cryogenic temperatures had not been previously studied in detail. How to go about fabricating uniform cryogenic targets was, therefore, something to be explored.

As the investigation progressed, a new system employing a cold helium jet only was desi red, whose freezing cell was maintained at room temperature. The ; sult was a very onactical and simple system capable of fabricating uniform cryogenic targets. This system is directly adaptable to current laser fusion target chambers and, therefore, adds a new dimension to the present laser fusion technology.

\section{1 - Cold Jets-Cold Chamber Combination}

The cold jets-cold chamber combination system has the distinct feature of spraying fresh cold helium gas jets directly onto the $\mathrm{O}_{2}$-filled glass microshell (Fig. 3). The two jets wet the target in opposite directions, and a mechanical pump continususly evacuates the cold gas filling the chamber. Another important: feature is that a heater wire surrounds the target for quick evaporation and refreeze of the $D_{2}$-condensate inside the target once it has been formed. This system was designed to study the behavior of a $D_{2}$-filled glass microshell, with no practical applications fo: 3 laser fusion reactor.

A glass microshell $\rightarrow 80 \mu m$ in diameter of $\sim 1 \mu m$ wall thickness and with $\square_{2}$ gas at 50 atm was used for the first experiment. As the temperature dropped 
below $18.7 \mathrm{~K}$ (triple point of $\mathrm{D}_{2}$ ), a nonuniform layer of solid $\mathrm{O}_{2}$ was seen, Pulsing current through the heater wire just enough to vaporize the $\mathrm{D}_{2}$-condensate and keeping the jets on fur quick refreezing caused a uniform layer of solid $\mathrm{d}_{2}$ to form. ${ }^{(9)}$ However, the thickness of the solid layer was less than $1 ; \pi$.

To achieve a thicker layer, a glass microshell filled with $D_{2}$ gas at 200 atm was used. However, since the wall thickness was greater than 5 um, and the mass of $\mathrm{D}_{2}$ gas was much higher than before, we could no longer achieve a uniform solid layer. This was mainly due to the fact that refreezing could not be made quickly enough. An interferance pattern of the $\mathrm{O}_{2}$-filled glass microshell monitored on the television screen clearly exhibited that, when the temperature surrounding the target was above $36 \mathrm{~K}$, no condensation took place. But as the temperature was lowered below $36 \mathrm{~K}$, a uniform liquid layer was formed. As the jet flowrate was raised and the temperature lowered, the thickness of the uniform liquid layer increased. An abrupt change occurred as the temperature decreased further: the liquid suddenly moved downward and collected at the bottom in the form of a droplet. When the heater wire was used to vaperize the $\mathrm{O}_{2}$-condensate, or the heat exchanger temperature raised by lowering the liquid helium Flowrate, the saine behavior was observed over and over again.

In order to understand this unique behavior, one is reminded of the fact that the surface tension force of hydrogen and its isutopes, i.e., $\mathrm{H}_{2}, \mathrm{D}_{2}$, and $T_{2}$, decreases as the temperature goes up, and vanishes at temperatures equal to or higher than the critical point $(10,11)\{F i g .14\rangle$. Consequent]y, the uniformity of the liquid $D_{2}$ layer depends largely on the extent that the wetting of the glass surface by liquid $D_{2}$ overpowers the surface tension and gravitational force effects. Within the limit of the experimental error, it appears that the effect of gravitational force is almost entirely negligible. 


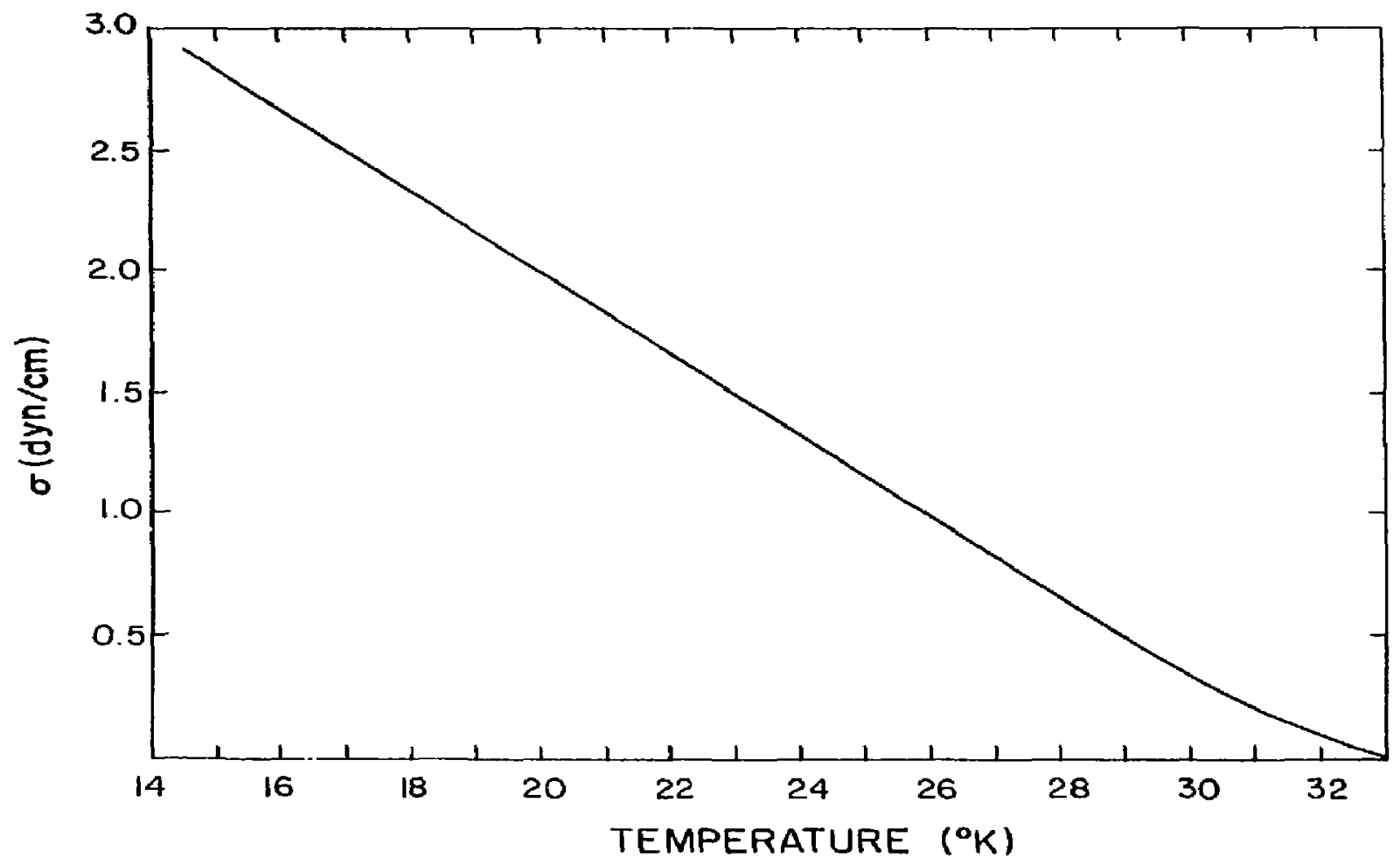

Fig. 14 - Surface tension of hydrogen. 
These experimental observations are very encouraging mainiy for two reasons: First, when there is no temperature gradient along the surface of the $\mathrm{D}_{2}$ filled glass microshe11, a uniform liquid layer is formed as lono as the wetting of the glass surface by liquid $D_{2}$ overpowers the surface tension. The thickness of the liquid layer can then be varied by changing the temperature, Second, a liquid layer is formed even when the cell pressure is 45 mTorr. Such 3 low pressure can give rise to sufficient thermal insulation, suppressing heat conduction from the outside world. Consequently, a successful operation of a target freezing apparatus having the chamber wall at room temperature becomes a realtistic possibility.

\section{2 - A Single Jet-Room Temperature Chamber-Combination}

This target freezing system (Fig. 4) has extremely useful potential applications for laser fusion. The system itself is very simple to build. The target is mounted in a room temperature chamber. So, firing of the taroet with laser beams is direct and straightforward. Keeping the cold jet on ailows the cryogenic target to retain its integrity as long as required for the laser illumination.

The jet nozzle has an inside diameter of 100 micrometers. By applying a low flow of cold helium gas, a pressure of less than 20 mTorr could be maintained inside the target freozing cell, with a 1000 liter per minute capacity mechanical pump simultaneously evacuating the cell. This means that the high vacuum required in the target chamber can be maintained while the cold jet is on.

The current system aiso has the capability of pulsing the cold jei for a predetermined time duration. This feature should allow one to achieve a very high vacuum in a big capacity chamber while the jet is off. Then oy turning on the jet for a required duration only to achieve a uniform i iquid iaver, the ores- 
sure inside the chamber would not increase by much.

Ir. the present experiment, a $\mathrm{D}_{2}$-filled glass microshell $\sim 200$ micrometers in diameter, of $\sim 7$ micrometer wall thickness, and with $\mathrm{O}_{2}-$ fill pressure of $\sim 200$ atm was us 'd. Figure 15 shows the setup inside the freezing cell. The single nozzle of cold helium gas jet is facing the target from the other side of the glass stalk. The thermocouple junction is placed close to, but below the target.

From room temperature a11 the way down to $36 \mathrm{~K}$, there was no folmation of O, -condensate inside the target (Fig. 16). At $36 \mathrm{~K}$ the onset of the formation of liquid condensate was observed (Fig. 17). Since the system is equinped with an $x-, y-$, and $z$-positioner so that the target can be moved around, the relative position between the jet nazzle and the target could be adjusted to give an optimal $7 \mathrm{~T}$ distribution around the target, (Fig. $18(\mathrm{a})$ ), which is required to form a uniform layer of $\mathrm{D}_{2}$-condensate. The pressure maintained in the freezing cell was very low: 75 mTorr), but the thickness of the resulting liquid layer was less than 0.5 micrometer. The target position had to be lowered relative to the jet nozzle to compensate for the gravity effect. Figure 18 (b) shows a nonuniform layer resulting from gravity and enforced by the cold jet. In contrest tu the cold chamber target freezing system described in the previous section, in this case, the narrow jet can not cool evenly the entire surface of the target. Therefore, the key parameter that determines the liquid layer uniformity is the gradient of the temperature (จT) along the target surface. Fi fure $19 \mathrm{iT}$ Tustrates the effect of a large $\nabla T$ which was set up using a higher jet flow. The position of the droplet can be determined by the resulting $\nabla T$, which depends on the relative position of the target with respect to the jet. Calculation of the fringe pattern observed at room temperature pre icts a glass wa71 thickness of -7 micrometers. On the other hand, calculation of the fringe pattern of an empty glass microshe1? (Appendix I) of 7 micrometer wall thickness gives the iringe 


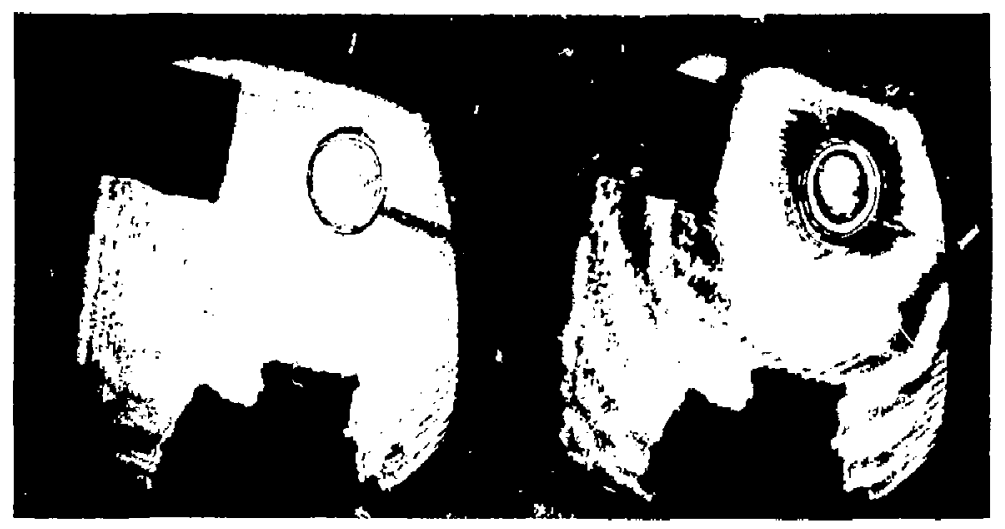

(a)

(b)

Fig. 15 - Picture of a target mounted on a glass stalk placed in front of the cold helium gas jet nozi?e. The thermocouple is seen below the target.

(a) Shadow micrograph; (b; interference micrograph.

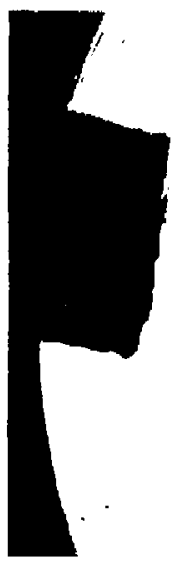

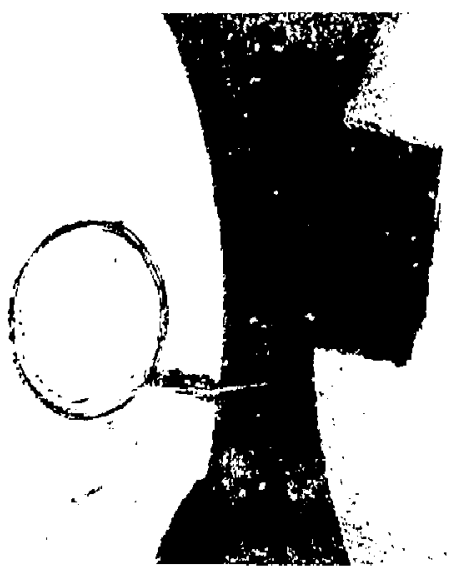

(a)

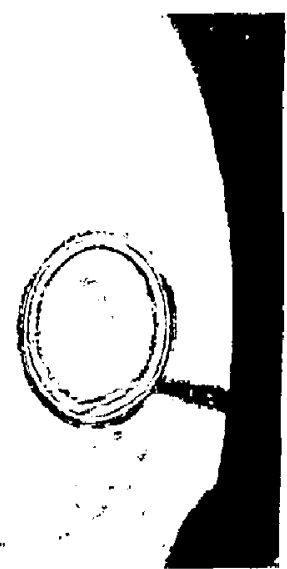

(b)

Fig. 16 - The target with no condensate. (a) Shadow micrograph; (b) Interference micrograph. 

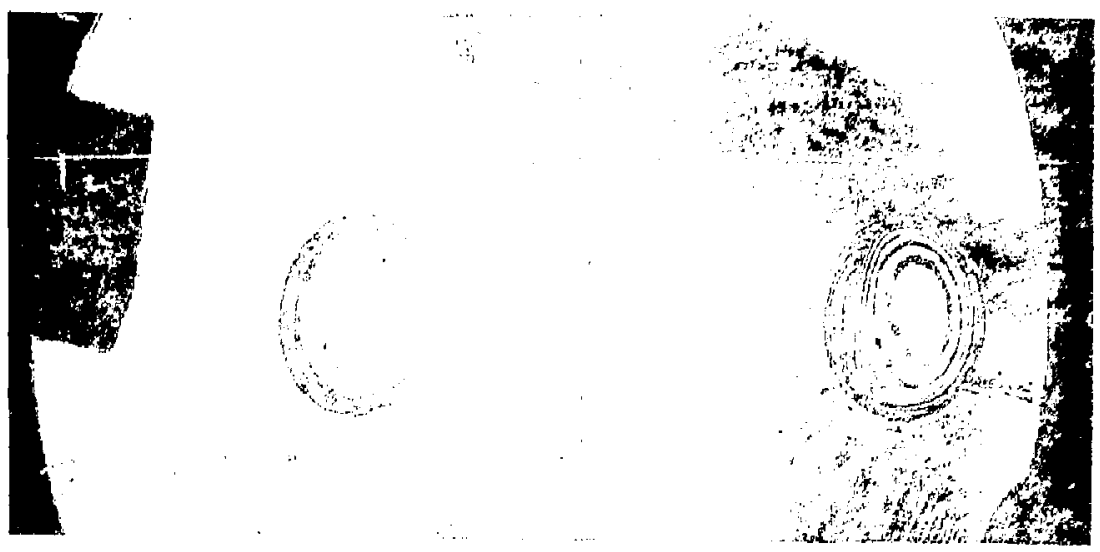

(a)

(b)

Fig. 17 - The beginning of condensation. (a) Shadow micrograph; (b) Interference micrograph.
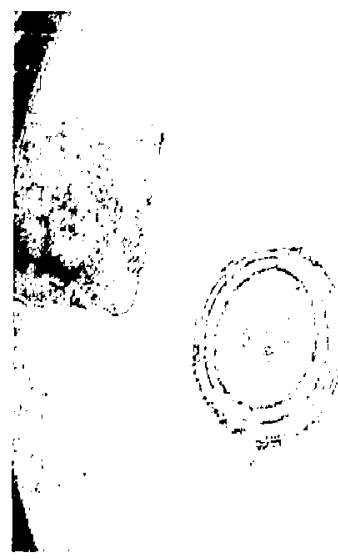

(a)

(b)

Fig. is - The effects of different positioning. (a) Uniform $D_{2}$-layer resulting from the $\nabla T$ along the target surface which compensates for gravity effect; (b) Nonuniform $D_{2}$-layer resul ting from nonuniform or along the target surface and gravity effect. 


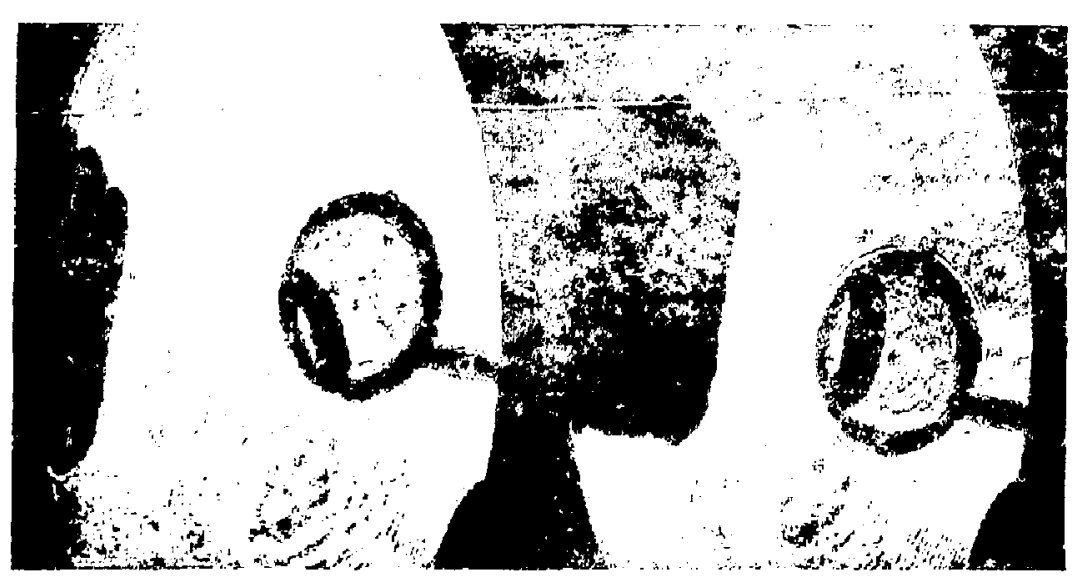

(a)

(b)
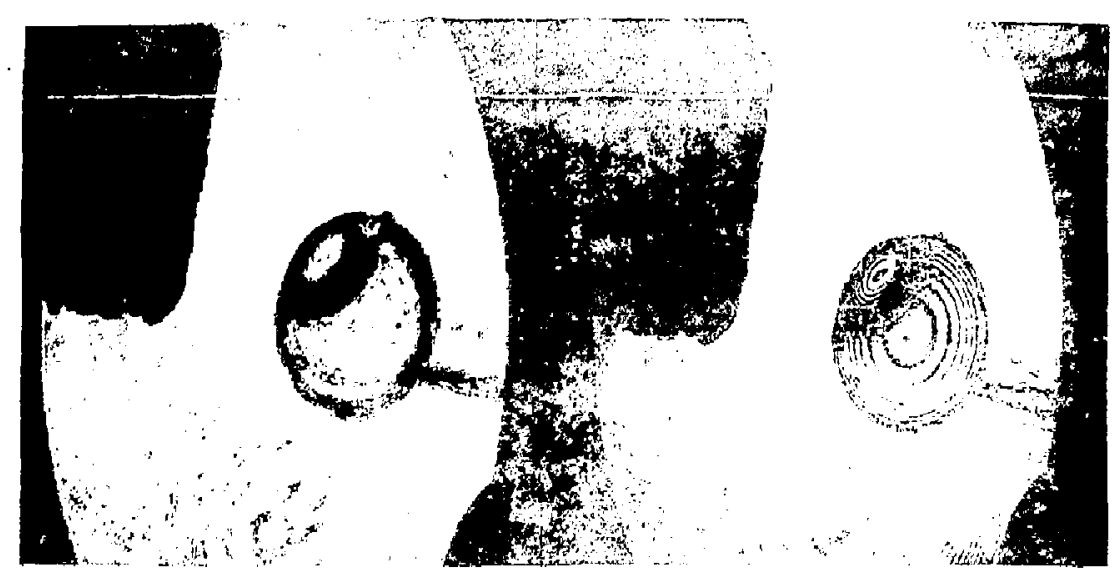

(c)

(d)

Fig. 19 - Droplet moved toward the nozzle opening.

(a) The jet cooling the lower part of the target;

(b) The jet cooling the front end of the target;

(c) The jet cooling the upper part of the target;

(d) Interference micrograph of $(c)$. 
pattern shown in Fig. 19 (d) (excluding the droplet iringe pattern). This means that there is no condensate of $\mathrm{D}_{2}$ other than the droplet inside the glass target.

Formation of the droplet occurred when the temperature of the target surface where the droplet is such that the higher surface tension of liquid $D_{2}$ overpowars the wetting force. As the target was moved away from the nozzle opening, two interesting effects took place. The target temperature was raised, so the tendency of the liquid was to spread out. The cross-sectional area of the cold jet hitting the target was much wider. This reduced the magnitude of the temperature gradient a Tong the surface by a substantial amount. Figure 20 shows the target with a uniform liquid layer of 5 micrometer thickness. To maintain such a thick layer, the jet flow had to be increased. Consequentiy, the freezing cell pressure went up to 60 mTorr. Moving the target away from the nozzle opening also creates a desirable situation from the standpoint of practical application, that is, a complete exposure of the target surface to the incident laser beams.

This approach for fabricating a cryogenic target is very promising for the following reasuns:

(1) It is directly adaptable inside the existing room temperature target chamber, with absolutely no need for adding cryogenic shields.

(2) Since the uniform liquid $D_{2}$ layer inside a target can be retained for as long as desired simpiy by maintaining the cold helium gas jet, the usual most troublesome constraint concerning the prolonged retention of the integrity of a cryogenic target for laser illumination no longer exists.

(3) Since the pressure of the target freezing cell as measured during the experiment is in the range of 50 mTorr, the current target fab- 


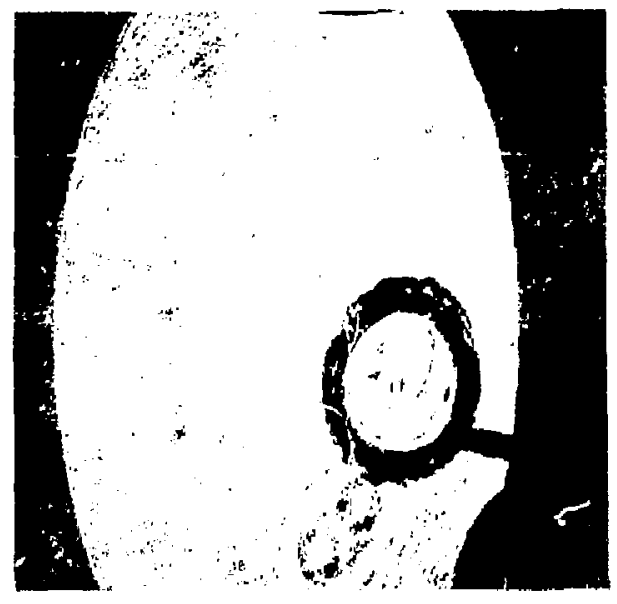

(a)

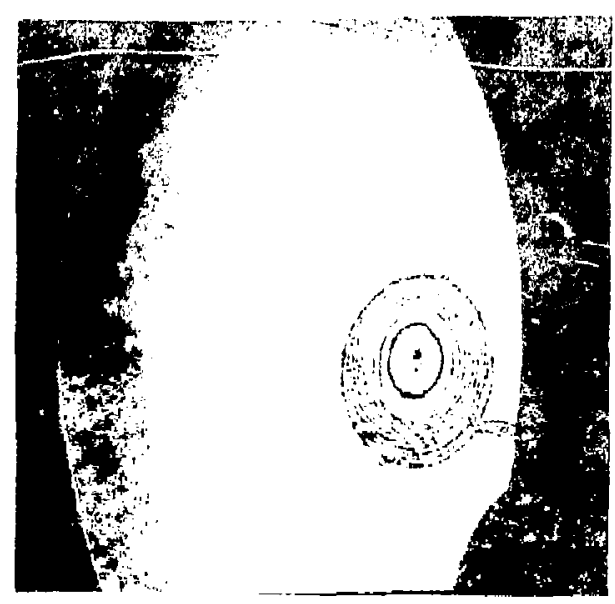

(b)

F:g. 20 - A thick layer of liquid $D_{2}$ which is uniform. (a) Shadow micrograph; (b) Interference micrograph. 
rication technique appears to be compatible as it is with the target chamber conceived for a future laser fusion power plant. Noting that the above pressure was affected by a modest size mechanical pump, it looks very oromising that wi th a more adequate means of vacuum-pumping one can further lower the pressure in the freezing cell to make it more compatible with the existing target chamber. If necessary, one can always shut off the cold helium gas flow before the laser shot by activating sle two electronic valves described in Chapter 2 (also Fig. 5). In this way, one can achieve very low pressure inside the target chamber if it is demanded for more accurate diagnostic measurements of laser target implosion. 


\section{CHAPTER 6}

CONCLUSIONS AND SUGGESTIONS FOR FUTURE EXPERIMENTS

The experiment described in this report started with a system that was capable of freezing $D_{2}$ gas contained in a glass microshell. But only under certain c :ditions could a solid uniform layer be formed: the glass microshell wall thickness had to be small (wl micrometer); the $D_{2}$-fill gas pressure at room temperature had to be low $(-100 \mathrm{~atm})$; and vaporizing of the nonuniform solid layer once it has been formed and refrozen had to be done fast. The observed behavior of the liquid layer, described in Chapter 5, has resulted in opening a new dimension in fabricating cryogenic targets. This technique of fabricating a uniform layer of liquid $\mathrm{D}_{2}$ inside a glass microshell (which should be equally applicable to other isotopes of hydrogen, including DT) is easy to implement with any target chamber configuration, and therefore forms the highlight of the present work.

Some of the important conciusions derived from the current investigation concerning fabrication of cryogenic targets are summarized in the following.

The mass densities of liquid OT and solid DT are the same in the practical sense. This means that, for target implosion by Taser beams, the effectiveness of imploding a mass of liquid or solid makes no difference. However, the vapor pressure of a liquid is much higher than that of a solid. This pressure produces a counter force to the implosion force. But when a target with a DT-fill gas pressure of $200 \mathrm{~atm}$ (at room temperature) is cooled down to $\sim 36 \mathrm{~K}$ (the point where condensate starts to form), the pressure inside the target is reduced to only $\sim 10 \mathrm{~atm}$. As one lowers the temperature even further to form more liquid, the vapor pressure also drops substantialiy. Advanced laser systems will produce a pressure of $\mathrm{M}^{8}$ atm on the surface of the taroet during implosion 
event. Therefore, in a practical sense, it should not make much difference whether the cryogenic target contains solid DT or liquid DT.

The advantages of using liquid DT are:

(1) The fabrication process is much simpler. The target temperature should be above $18.7 \mathrm{~K}$ (triple point of $\mathrm{D}_{2}$; for fabrication of a solid layer the target temperature should be below $18.7 \mathrm{~K}$, triple point). The uniformity of the liquid layer is guaranteed as long as the wetting of the glass surface by liquid $\mathrm{O}_{2}$ overpowers the surface tension. No special means is needed to obtain a uniform liquid layer.

(2) The thickness of the liquid layer can be controlled by controlling the target temperature. This feature is particulariy appealing, because one can produce targets of varying aspect ratios to test their efficiencies in giving rise to fision reactions. For a given power density of the laser beams incident on the surface of the target, the fusion energy released is expected to be a function of the thickness of the DT layer. The peak of the released energy should occur when the thickness of the DT layer is somewhere between zero (no condensate) and the radius of the target (solid target).

(3) A perfect DT Tiquid layer can be obtained when the target is placed in an environment free from gravity. Such a condition can be easily achieved when the target is in free fall. Since future laser fusion reactors would have to operate on a continuous basis, refueting of such ractors could therefore be done by letting the cryogenic laser targets enter the reactors in free-fall fashion at a control led injection speed. 
(4) The transport of cryogenic targets to the center of a fusion reactor in a power plant can face the difficulty of not having the desired target due to their snort lifetime. By first cooling the targets to $4.2 \mathrm{~K}$ (boiling point of helium) to form a nonuniform solid layer, and then letting them fall into the reactor, one could, however, resolve this difficulty, because on the way down the targets would heat up resulting in liquefaction of the initially forzen nonuniform DT-7ayer into a uniform liquid layer. Since a uniform liquid layer would be obtained at temperatures below $36 \mathrm{~K}$, and if the target speed is preselected so that the target will reach the center of the reactor when it is at its optimal temperature (for formation of right liquid layer thickness), successful fueling of a laser fusion reactor will be achieved. Collection of data regarding free-fall of cryogenic targets at different temperatures and pressures would therefore be very iseful.

Finally, some suggestions concerning future inves cigations are in order. Inspection of the fringe image of a target requires a more quantitative means of checking the symmetry. The proposed system that uses the analog signal out of a television camera (see Chapter 4, Section 5) is a promising one. There are some other techniques that can be used for the diagnostics of the interference fringe patterns of the target.

(1) Using the advantage of holography to record amplitude and phase of a monochromatic light wave of an object, one can record the wave of the target on a holographic plate, develop it, and position it at the same place, so that the virtual image and actual target image will be overlapped with no fringes seen (fig. 21). Then, by rotating the target, one should be able to detect the nonuniformity of a DT-1ayer thickness 

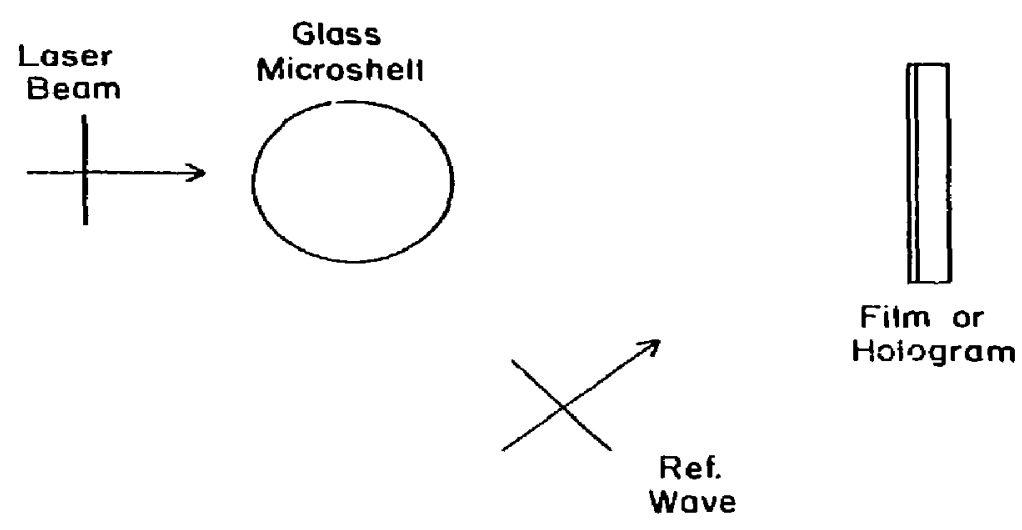

Fig. ¿1 - The optical setup using holography. 
by the amount of fringes that appear on the resulting image.

$$
\Delta S=\Delta W \cdot(n-1)
$$

where $\mathrm{sw}$ - change in thickness

$n$ - incex of refraction of a detected layer

$\Delta S$ - optical path length difference

(e.g., for $n=1.5$ and $\Delta w=1.2656$ micrometer, and with $\lambda=6328 \AA$ using a He-Ne laser, as $=6328 \mathrm{~A}$, which means a singTe fringe would appear).

This scheme enables one to inspect the entire tarqet. The main drawback in implementing this scheme could be that it requires an extremely sensitive mechanism for ratating the target.

(2) Since the geometry of the target is such that toward the edge the density of the fringes gets very high, which makes it difficult to obtain a quantitative analysis, the following method can be employed:

(a) Recording the fringe pattern on a holographic plate (holographic plates have much higher resolution than reguiar film).

(b) Obtaining optically the spatial Fourier transform of the fringe pattern. Figure 22 illustrates the optical setup.

The density of the fringe patterns toward the edge of the batl can first be presented at the highest spatial frequency on the input plane. Then, by taking the Fourier transfomation of the input plane, the pattern on the output plane will represent the spectrum of the input 5:?tial frequency. Fluctuations of the circular patterns on the output plane witl therefore correspond to the nonuniformity along the edge of the target. 
宣正自 


\section{APPENOIX I}

COMPUTER PRMITOUT OF THE CALCLLATED FRINGE PATTERNS

This appendix includes two computer programs and their printouts of the caiculated fringe patterns.

The printout is of the fringe patterns along the radius of the taroet.

(1) The first fringe pattern is of a glass microshel1 of $100 \mathrm{um}$ radius, with no gas inside. The glass thickness varies from $0.5 \mathrm{zm}$ up to $15 ; \mathrm{m}$.

(2) The second printout is of the same glass micrcshell, but filled with $186 \mathrm{~atm}$ or $30 \mathrm{mg} / \mathrm{CC}$ of $\mathrm{O}_{2}$ gas.

Matching the observed fringe pattern of the target at mom temperature with printout number 2 gives the target giass thickness. Comparing the fringe pattern of the same target containing a droplet (excluding the droplet fringe pattern) against printout number $l$ gives the same glass thickness that is obtained from printout number 2 . This verifies that there is no liquid inside the target besides the droplet. 


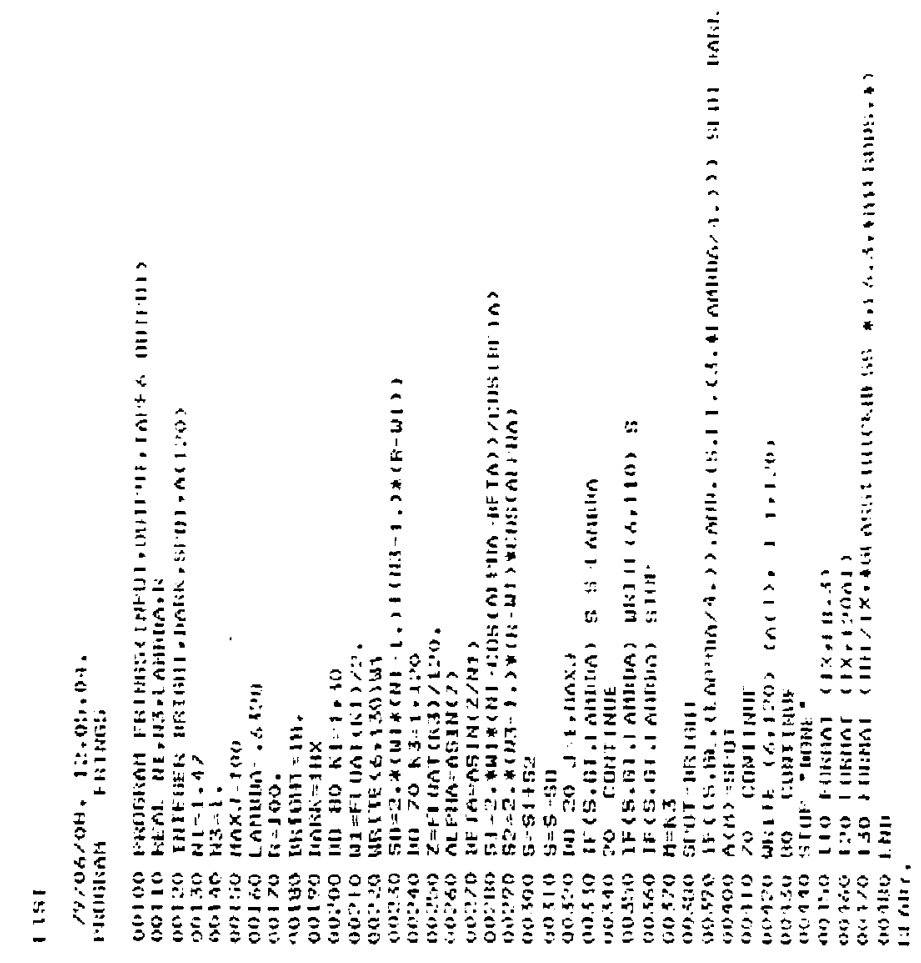




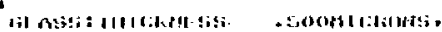

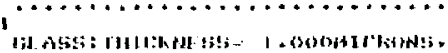

atr.

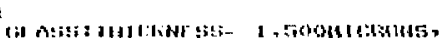

…....................

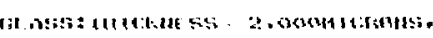

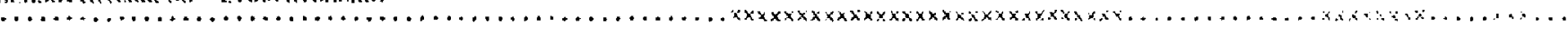

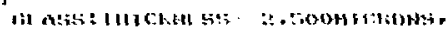

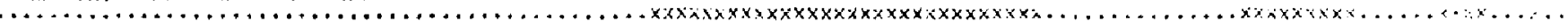

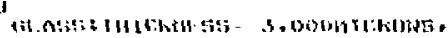

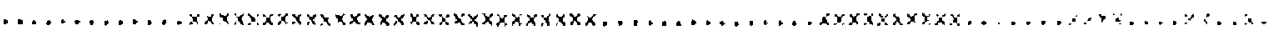

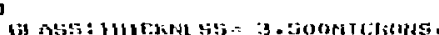

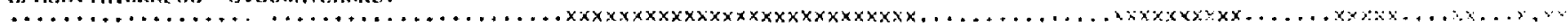

in nes: om

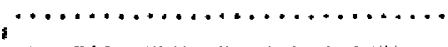

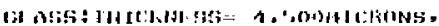

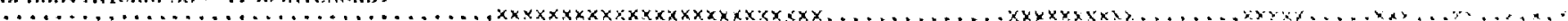

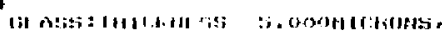

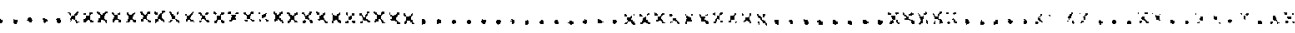

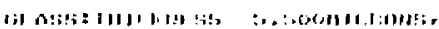

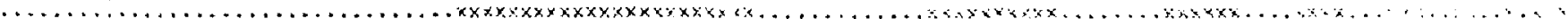
!:

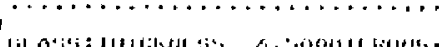

19.6.

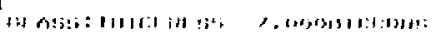

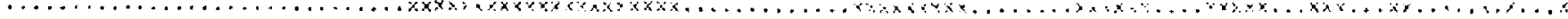

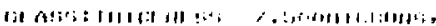

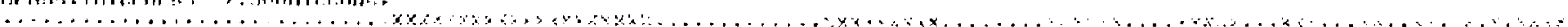




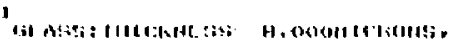

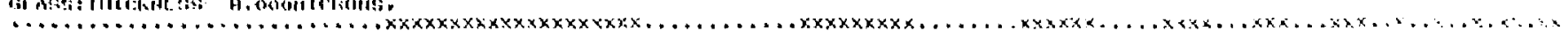

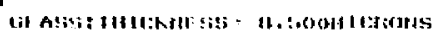

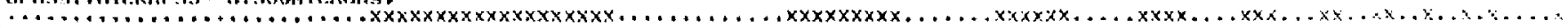

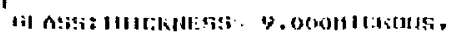

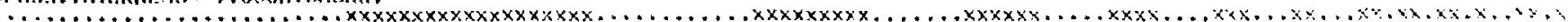

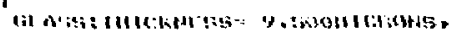

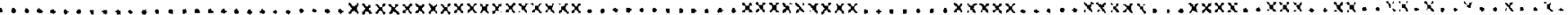

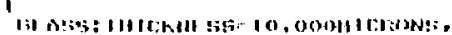

.

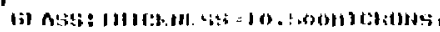

烈

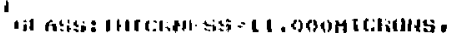

.

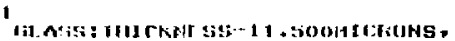

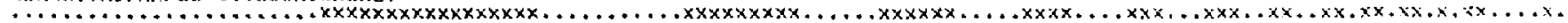

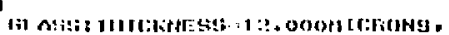

$\ldots$

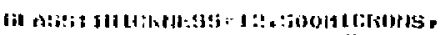

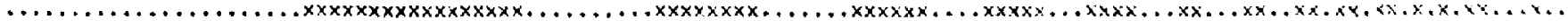

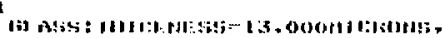

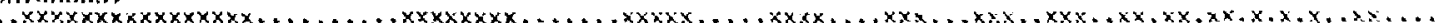

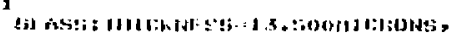

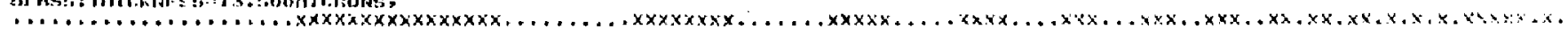

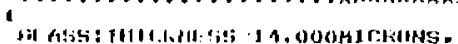

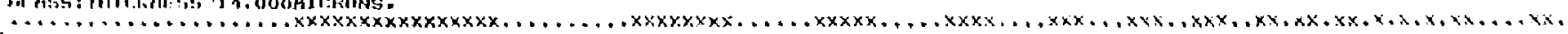

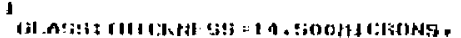

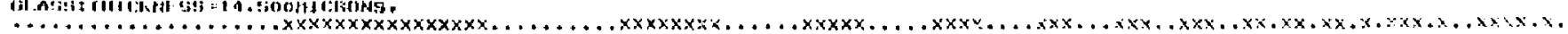

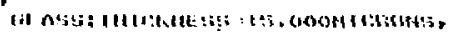

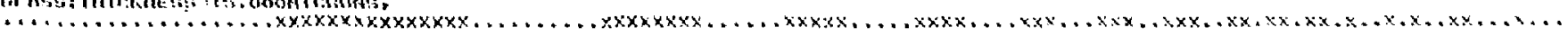

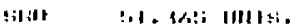

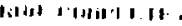




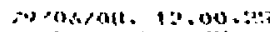

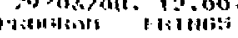

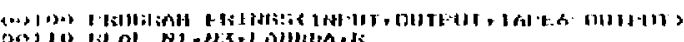

(1)

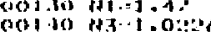

$\operatorname{lin} x+100$

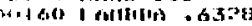

and $210-100$

(4)

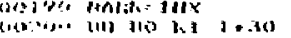

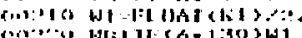

$(0 .)^{2}$ s)

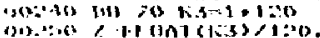

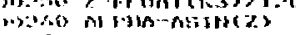

(1):20

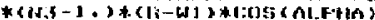

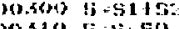

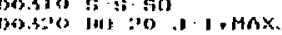

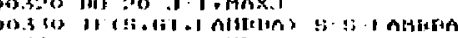

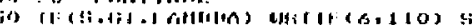

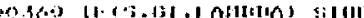

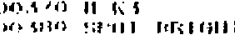

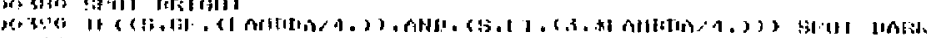

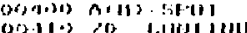

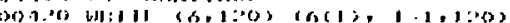

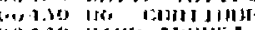

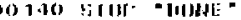

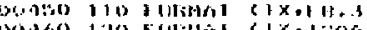

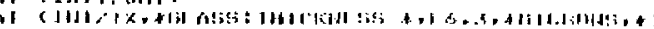

(i) 1311,1 
............................

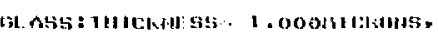

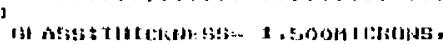

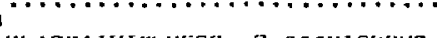

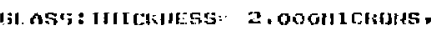

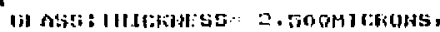

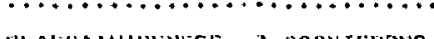

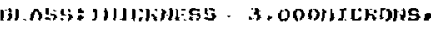

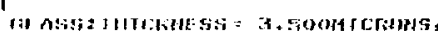

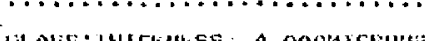

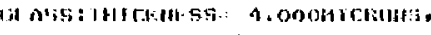

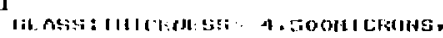

'

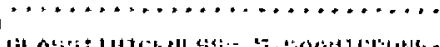

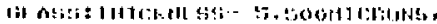

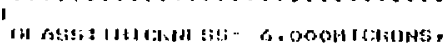

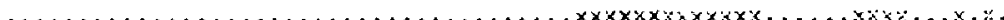

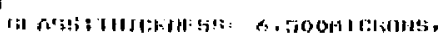

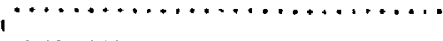

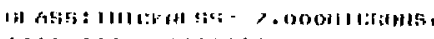

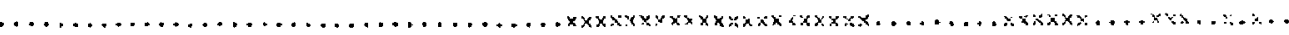

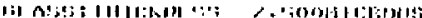




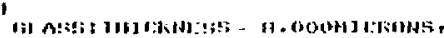

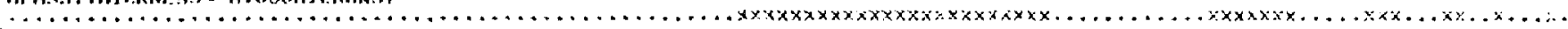

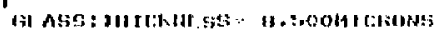

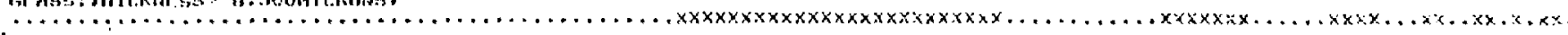

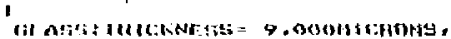

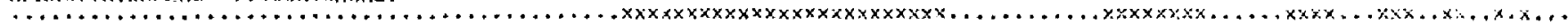

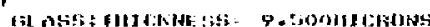

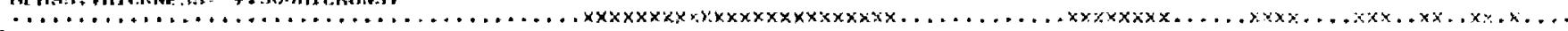

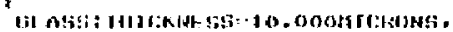

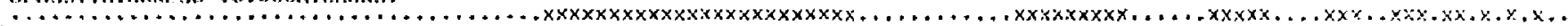

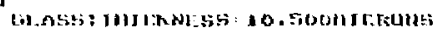

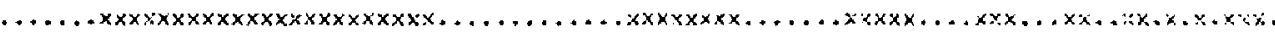

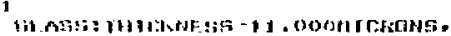

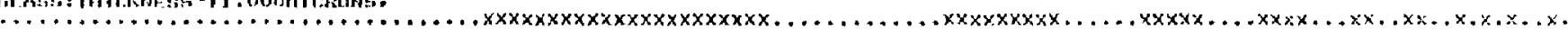

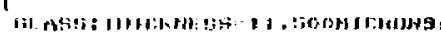

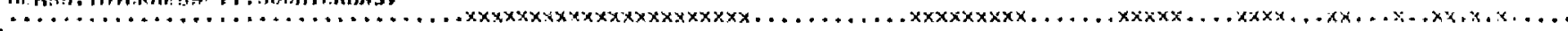

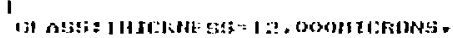

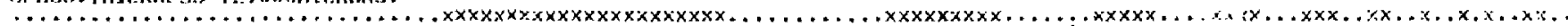

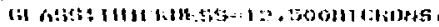

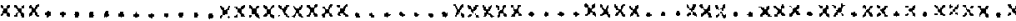

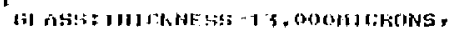

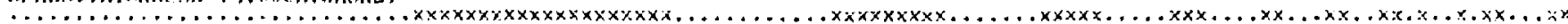

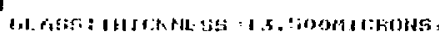

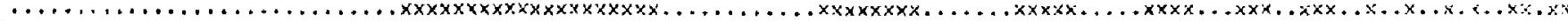

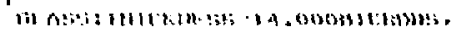

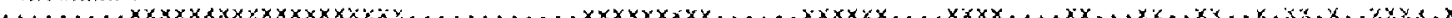

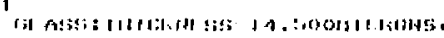

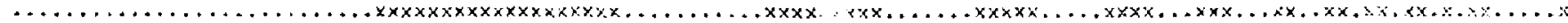

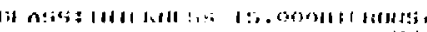

tilll AH, onto Ittlat.

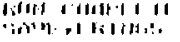




\section{APPENDIX II \\ THEORETICAL CALCULATION OF THE AMOUNT OF $D_{2}$-CONDEHSATION INSIDE A TARGET}

This appendix contains calculations which, under simplifying assumptions, determire the following properties of a $\mathrm{D}_{2}$-filled target at different cryogenic temperatures:
(1) The $D_{2}$ gas pressure
(2) The thickness of the $\mathrm{D}_{2}$ liquid layer
(3) The index of refraction of the $\mathrm{D}_{2}$ gas and liquid.

A) Mass Density-to-Pressure-Conversion

$$
\rho=\frac{M}{V}
$$

where $p$ is the mass density of $D_{2}$ in $\left[\mathrm{kg} / \mathrm{m}^{3}\right]$

$M$ is the total mass of $D_{2}$ in $[\mathrm{Kg}]$

and $V$ is the volume of $\mathrm{O}_{2}$ in $\left.\mathrm{Cm}^{3}\right]$.

For $\mathrm{D}_{2}$ with atomic number 4 :

$$
M=(N) \cdot(4) \cdot\left(1.67 \times 10^{-27}\right)
$$

where $N$ is the number of particles,

therefore,

$$
\rho=\frac{N}{V}\left(6.68 \times 10^{-27}\right)
$$

Using the ideal gas law

$$
P=\frac{N}{V} k T
$$


where $k$ is Boitzmann's constant in $[J / k]$

$T$ is the temperature in [ $K$ ]

and $P$ is the pressure in $\left[N / m^{2}\right]$.

Using the ratio $\frac{N}{V}$ from Eq. (A.2)

$$
P=\left(\frac{\rho}{6.68 \times 10^{-27}}\right) \cdot\left(1.38 \times 10^{-23}\right) \cdot T=2066 \mathrm{DT}
$$

(e.g., for $o=30 \mathrm{mg} / \mathrm{cc}$ the pressure at room temperature is $P=186 \mathrm{~atm}$ ).

B) Mass Density-to-MolecuTar Density-Conversion

A different form of Eq. (A.2) is

$$
\begin{aligned}
& \frac{N}{V}=\frac{D}{6.68 \times 10^{-27}} \\
& Q=\frac{0 / 6.68 \times 10^{-27}}{6.023 \times 10^{23}}=2490
\end{aligned}
$$

where $Q$ is the molecular density in $\left[\right.$ moie/ $\left./ m^{3}\right]$,

e.g., for $O=30 \mathrm{mg} / \mathrm{cc}$ the molecular density is $Q=7470 \mathrm{~mole} / \mathrm{m}^{3}$.

C) Density-Dependence of the Index of Refraction of $\mathrm{D}_{2}$

A formula can be derived to approximate the index of refraction, $n$, from Fig. 1 of Reference 9.

$$
n=1+\frac{0.0226}{7470} \cdot Q=1+3.025 \times 10^{-6} Q
$$

or

$$
n=1+0.753 \times 10^{-3}
$$


D) Temperature-Dependence of the Density of $\mathrm{O}_{2}$

\begin{tabular}{ccc}
$\begin{array}{c}\text { Temperature } \\
\text { (K) }\end{array}$ & \multicolumn{2}{c}{ Density } \\
& (Mol/Liter) \\
& Vapor & Liquid \\
\hline & & \\
18.770 & 0.111221 & 43.1598 \\
19.000 & 0.124876 & 43.0160 \\
20.000 & 0.181841 & 42.5081 \\
21.000 & 0.256456 & 41.9781 \\
22.000 & 0.352051 & 41.4228 \\
23.000 & 0.472322 & 40.8403 \\
24.000 & 0.621418 & 40.2287 \\
25.000 & 0.804045 & 39.5858 \\
26.000 & 1.02561 & 38.9085 \\
27.000 & 1.29242 & 38.1926 \\
28.000 & 1.61194 & 37.4326 \\
29.000 & 1.99316 & 36.6212 \\
30.000 & 2.44712 & 35.7488 \\
31.000 & 2.98769 & 34.8025 \\
32.000 & 3.63281 & 33.7643 \\
33.000 & 4.40659 & 32.6085 \\
34.000 & 5.34403 & 31.2963 \\
35.000 & 6.49920 & 29.7650 \\
36.000 & 7.97036 & 27.9000 \\
37.000 & 9.98197 & 25.4469 \\
38.000 & 13.4367 & 21.4462 \\
38.340 & 17.3280 & 17.3280 \\
& & \\
\hline & &
\end{tabular}

E) Thickness of the Liquid Layer

The total mass, $M$, of the $D_{2}$ contained inside a ball is

$$
M=\rho_{0} \cdot v=\rho_{0} \cdot \frac{4}{3} \pi\left(R-w_{1}\right)^{3}
$$

where $y$ is the volume of the ball occupied by the $D_{2}$ gas,

$\theta_{0}$ is tha gas mass density with no condensate,

$R$ is the radius of the ball,

and $w_{1}$ is the thickness of the glass shell. 
Using the assumption that $w_{2} \ll R$, with $w_{2}$ being the thickness of the liquid layer, the mass of the gaseous $\mathrm{D}_{2}$, ilg, can be approximated as

$$
M g \approx \rho_{g} \cdot V=\rho_{g} \cdot \frac{4}{3} \pi\left(R-w_{1}\right)^{3}
$$

where $o_{g}$ is the $\mathrm{O}_{2}$-vapor mass density at a given temperature.

The mass of the liquid $D_{2}, M_{l}$, is then

$$
H_{C}=M-M g
$$

The mass density of liquid $\mathrm{O}_{2}$ is $\mathrm{pl}_{\ell}$.

The volume of the liquid, $V_{l}$, using Eqs. (A.9), (A.10), and (A.11) is

$$
V_{l}=\frac{M_{e}}{\rho_{l}}=\frac{\left(o_{0}-o_{g}\right) \frac{4}{3} \pi\left(R-W_{q}\right)^{3}}{o_{l}}
$$

The thickness of the liquid $D_{2}$ layer, $w_{2}$, can therefore be estimated as

$$
v_{l}=4 \pi\left(R-w_{1}\right)^{2} \cdot w_{2}=\frac{\left(p_{0}-p_{q}\right) \frac{4}{3} \pi\left(R-w_{1}\right)^{3}}{p_{l}}
$$

or

$$
w_{2}=\frac{\left(\rho_{g}-\rho_{g}\right)\left(R-w_{1}\right)}{3 p_{l}} .
$$


REFERENCES

1) F. Chen, Introduction to Plasma Physics, Plenum, N. Y. (1974).

2) Lectures From the Argonne Faculty Institute on Fusion Plasmas (1975) (Chapter T).

3) J. Nuckolls, L. Wood, A. Thiessen, and G. Zimmerman, Nature 239, 139 (1972).

4) T. M. Henderson, R. B. Jacobs, D. E. Solomon, and G. H. Wuttke, Adv. in Cryo. Eng. 21, 455 (1975).

5) A. Rosencwaig, J. L. Dressler, J. C. Koo, and C. D. Hendricks, University of California report UCRL-81421 (1978).

6) B. H. Weinstein, and C. D. Hendricks, Interferometric Measurements of Laser Fusion Targets, University of California, Lawrence Livermore Laboratory, private communication (1977).

7) C. K. Briggs, R. T. Tsugawa, C. D. Hendricks, and P. C. Souers, University of California report UCRL-51921 (1975).

8) C. Souers, Cryogenic Properties of Heavy Hydrogen, Chemistry Department, Lawrence Livernore Laboratory, California, private communication (1973).

9) K. Kim, B. J. Smoot, R. L. Woerner, and C. D. Hendricks, Appl. Phys. Lett. 34, $282(1979)$.

10) Yu. P. Blagoi, and V. V. Pashkov, Soviet Physics-JETP 22, 999 (1966).

17) V. N. Grigorev, and N. S. Rudenko, Soviet Physics-JETP 20, 63 (1965). 